\title{
QS能
}

\section{EQUIDAD Y SOSTENIBILIDAD: UNA PROPUESTA PARA COMPLETAR LA REFORMA DEL SISTEMA ESPAÑOL DE PENSIONES CONTRIBUTIVAS}

Asegurar el riesgo de ingresos durante la vejez, para evitar la dependencia económica de la población al término de la etapa de actividad laboral, y el riesgo de pérdida brusca de ingresos de sus familiares directos a la muerte del titular es la función del segundo pilar en los modernos sistemas públicos de pensiones contributivas. La equidad distributiva y la sostenibilidad a largo plazo de los mismos resultan imprescindibles para garantizar su apoyo estable en los países democráticos, sin el cual los sistemas de pensiones estructurados bajo el principio de reparto no pueden subsistir. La ausencia de equilibrio actuarial o su deterioro paulatino, los shocks demográficos y el envejecimiento de la población son otras tantas amenazas al juego de restricciones que enmarcan la existencia de estos sistemas, cuyo fundamento es el equilibrio entre ingresos y gastos, actual y proyectado. En este trabajo se somete el sistema español de pensiones contributivas a diferentes pruebas de equidad y sostenibilidad, a la vista de las proyecciones disponibles, bajo distintos escenarios. Una vez detectadas las fragilidades existentes, se analiza el impacto de las últimas reformas y se propone la forma de completarlas con una batería de cuatro medidas para poner remedio a las mismas y restablecer los equilibrios a medio y largo plazo.

Palabras clave: pensiones públicas, presupuesto, jubilación.

Clasificación JEL: H55, H61, J26.

\section{Introducción}

Los sistemas contributivos de pensiones públicas constituyen el mecanismo más generalizado en las sociedades avanzadas para compartir colectivamente el riesgo de ingresos durante la vejez —al término de la etapa de actividad económica y laboral-, distribuyendo el flujo de ingresos obtenidos por los hogares a lo

*Consejero Técnico. Dirección General de Política Económica. Versión de julio de 2017. largo del ciclo vital de sus miembros con el fin de que alcancen un nivel adecuado por sí mismos, evitando que durante esa etapa de la vida las personas mayores se encuentren en situación de dependencia económica. Adicionalmente, el riesgo cubierto alcanza también a las situaciones de muerte del titular y supervivencia de su cónyuge, hijos y —residualmente- de otros familiares dependientes de sus ingresos ${ }^{1}$.

1 En este trabajo solo se incluyen las pensiones de incapacidad cuando son percibidas a partir de la edad legal de jubilación, ya que en el sistema español a esa edad se transforman en pensiones de jubilación. 
En un trabajo anterior se ha estudiado el espacio que ocupan estos sistemas dentro del estado de bienestar, las principales características o "dimensiones» de este último y de los diferentes sistemas de pensiones, analizando los mecanismos más adecuados para identificarlas y para modelizar su grado de equidad generacional y sostenibilidad, realizando un primer intento de aplicación del modelo a la evaluación de los niveles de equidad actuarial intrageneracional de dos de los principales sistemas de pensiones vigentes en la Unión Europea: el sueco y el alemán (Espina, 2017a).

En un segundo trabajo se ha estudiado el sistema español de pensiones, describiendo sus tres principales componentes y reconstruyendo la evolución de las principales variables durante el período en que se dispone de datos homogéneos, que alcanza a los últimos cuarenta años para el sistema de pensiones contributivas, cubriendo completamente la etapa postconstitucional durante la que se configuraron los rasgos principales del sistema vigente. Se identificaron también los principales parámetros y tendencias que afectan a esta evolución, haciendo énfasis especial en la dinámica de la ratio de reposición (también denominada tasa de sustitución o de reemplazo) y del denominado «efecto de sustitución» (Espina, 2017b).

En las tres primeras partes de este trabajo se estudia el equilibrio actuarial del sistema español de pensiones contributivas de jubilación, viudedad y supervivencia, aplicando el modelo de análisis ya mencionado a las diferentes formas de medición de la ratio de reposición y a los diferentes bloques de pensiones, diferenciando en lo posible el conjunto del sistema de su Régimen General, dado el papel que desempeña este último como «punto de fuga» para aquel. Mientras que con las versiones más comunes de la ratio de reposición el equilibrio actuarial del sistema parece incuestionable, con las versiones más acuradas resulta dudosa, muy especialmente cuando se analiza el Régimen General en relación con el coste salarial, como se hace en la cuarta parte.

En cambio, la quinta parte pone de manifiesto la falta de equidad intergeneracional del sistema y su carácter insostenible, dada la evolución previsible de la «ratio de capacidad», que se identifica como la clave de bóveda de la sostenibilidad realizando una proyección de las principales variables, tomando ya en consideración la reforma de la edad de jubilación de 2011 y prolongándola en el tiempo. La sexta parte del trabajo estudia la idoneidad de la reforma de 2013 para corregir el problema de sostenibilidad y las dos partes últimas propongan mecanismos alternativos para alcanzar simultáneamente la equidad intergeneracional y la sostenibilidad del sistema, completando tal reforma.

\section{El equilibrio actuarial del sistema español de pensiones de jubilación}

EI Cuadro 1 aplica las dos primeras ecuaciones del modelo de equilibrio generacional estudiadas en Espina (2017a) al caso de España tomando como cotizante y jubilado representativo aquel cuya carrera coincide con la estadística o la media de la nómina de pensiones más reciente (Espina, 2017b). Como tipo de cotización $(T)$ se toma el que resulta de aplicar al tipo de cotización por contingencias comunes $(28,3$ por 100) la proporción que representa el $D$

2 Pro memoria: [1] $F P=T \cdot w \cdot\left[(1+i)^{\mathrm{n}}-1\right] / i$. Sin embargo, en lo que se refiere al $C P$, eliminaremos por el momento el coste de la viudedad, resultando: [2] $C P=\sigma \cdot w \cdot\left[(1+i)^{\eta}-1\right] /\left[i \cdot(1+i)^{\eta}\right]$. 
CUADRO 1

EQUILIBRIO ACTUARIAL INERCIAL DEL SISTEMA DE PENSIONES DE JUBILACIÓN CON AÑOS DE COTIZACIÓNY ESPERANZA DE VIDA FIJOS

\begin{tabular}{|c|c|c|c|c|c|c|}
\hline \multicolumn{7}{|c|}{ Tipo de cotización para la pensión de jubilación } \\
\hline Fondo-Pensión & $20 \%$ & & & & & \\
\hline$i=0,01$ & 9,0 & & & & & \\
\hline$i=0,015$ & 9,9 & & & & & \\
\hline \multicolumn{7}{|c|}{ Ratio de reposición de la pensión de jubilación } \\
\hline Capital-Pensión & $48,6 \%$ & $50,0 \%$ & $55,0 \%$ & $60,0 \%$ & $65,0 \%$ & $70,5 \%$ \\
\hline$i=0,01$ & 9,2 & 9,4 & 10,4 & 11,3 & 12,3 & 13,3 \\
\hline$i=0,015$ & 8,7 & 9,0 & 9,9 & 10,8 & 11,6 & 12,6 \\
\hline \multicolumn{7}{|c|}{ Equilibrio del fondo de pensiones de jubilación } \\
\hline \multicolumn{7}{|l|}{$F P-C P$} \\
\hline$i=0,01$ & $-0,2$ & $-0,5$ & $-1,4$ & $-2,4$ & $-3,3$ & $-4,4$ \\
\hline$i=0,015$ & 1,2 & 0,9 & 0,0 & $-0,9$ & $-1,8$ & $-2,8$ \\
\hline Proyección año & 2016-2022 & 2025 & 2033 & 2042 & 2050 & 2059 \\
\hline
\end{tabular}

gasto en pensiones de jubilación sobre el gasto total en pensiones en marzo de $2017(0,706)$. Como tipo de capitalización o rendimiento $(i)$ se han examinado dos opciones (1 y 1,5 por 100), equivalentes al crecimiento esperado del PIB real a largo plazo, horquillando el crecimiento anual registrado durante el siglo XXI (1,4 por 100), muy próximo a la hipótesis superior, o escenario optimista ${ }^{3}$. Además, en caso de que se mantuviera la participación de los salarios en la renta nacional, ese sería también el crecimiento del salario real y de las cotizaciones. No es preciso por el momento hacer simulaciones sobre el salario medio $(w)$ ni sobre la inflación, pues todos los cálculos de estos cuadros toman como unidad el salario anual a precios corrientes, por lo que las cifras resultantes son múltiplos o fracciones del mismo. El período de cotización es el proporcionado por la Tesorería

\footnotetext{
3 En las proyecciones de la Comisión Europea (2015a), 1,4 por 100 es la tasa de crecimiento prevista para el PIB potencial y la productividad del trabajo en España durante el período 2013-2060. En cambio, según las estimaciones de Brío et al. (2016) la tasa interna de retorno del sistema español de pensiones (computando la totalidad de las mismas) es del 3,1 por 100 , de modo que su sostenibilidad a largo plazo exigiría un crecimiento del PIB superior al 3 por 100, lo que duplica nuestra hipótesis base.
}

General de la Seguridad Social como período medio de cotización de las altas en pensiones de jubilación en el año 2016 ( $n=37,22$ años). Bajo estos supuestos, el fondo acumulado para la pensión de jubilación (FP) a lo largo de la vida laboral media de ese año oscilaría entre 9 y 9,9 veces el salario anual.

Como ratio de reposición ( $\sigma$, también denominada de sustitución o de reemplazo) se han examinado cinco supuestos. El primero $(48,6$ por 100) se corresponde con la ratio pensión anual media de jubilación/coste laboral total anual por trabajador (total sectores) efectivamente registrada durante el año 2016. Las otras cinco opciones (entre 50 y 70,5 por 100) se corresponden con las ratios resultantes de extrapolar la tendencia lineal de esa ratio a lo largo de los últimos 35 años, que, de mantenerse la tendencia inercial, se alcanzarían en los años 2025, 2033, 2042, 2050 y 2059-2060, respectivamente. La esperanza media de vida a la edad de jubilación ( $\eta$ ) es la media de las de los dos sexos, según el INE (21,03 años). En estas condiciones el capital-pensión necesario para hacer frente a las anualidades $D$ 
de jubilación se situaría actualmente entre 9,2 y 8,7 salarios anuales, lo que significaría que en la hipótesis de crecimiento mínimo (1 por 100) se estaría ya incurriendo en un déficit de 0,2 anualidades (que llegaría a situarse en 4,4 anualidades si la ratio de reposición media llegase al 70,5 por 100 , cosa que ocurriría en 2050-2060 de mantenerse la tendencia lineal de crecimiento observada hasta ahora). En cambio, en la hipótesis de crecimiento del 1,5 por 100 anual el superávit actual equivaldría a 1,2 anualidades de salario, el equilibrio se alcanzaría en 2033 y en 2059 el déficit sería de 2,8 anualidades de salario por jubilado (a 2 y $1,1$, con crecimientos de 1,75 y 2 por 100$)$.

\section{El enigma pensiones/pensionistas de viudedad y el equilibrio actuarial de las pensiones de jubilación y viudedad}

Al examinar la nómina mensual de las pensiones y pensionistas de viudedad aparece una anomalía que conviene explicar. En el mes de marzo de 2017, en esa nómina figuraban 2.357.691 pensiones pero solo 1.658.683 pensionistas, con una diferencia de casi 700.000 entre una y otra cifra (un 30 por 100 de las pensiones), como figura en el Gráfico 1.

Todas las clases de pensiones presentan diferencias entre esas dos cifras, pero de un orden completamente menor (en jubilación, por ejemplo, la diferencia es del 2,4 por 100, y en incapacidad, menos de la mitad de esa cifra). La diferencia en este caso se debe a que las pensiones de viudedad son compatibles con la percepción de las pensiones de incapacidad o jubilación a que el beneficiario pueda tener derecho individual, sometida esta concurrencia a los límites máximos y mínimos fijados anualmente, de modo que en la inmensa mayoría de estos casos la de viudedad se convierte de hecho en un complemento de aquellas pensiones (fundamentalmente para las mujeres, dada la distribución por sexos que se observa en el $\triangleright$

GRÁFICO 1

NÚMERO DE PENSIONISTAS Y DE PENSIONES DE VIUDEDAD POR GRUPOS QUINQUENALES DE EDAD MARZO DE 2017

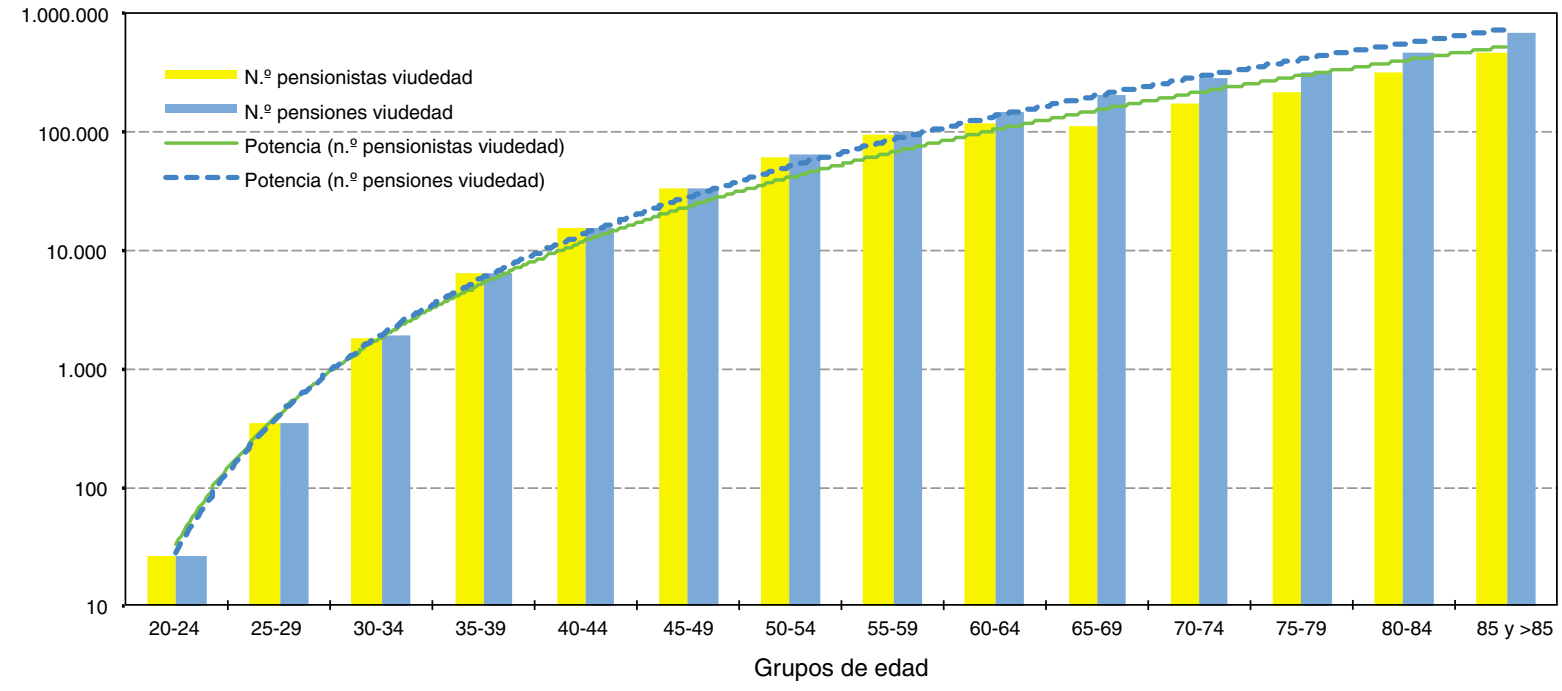




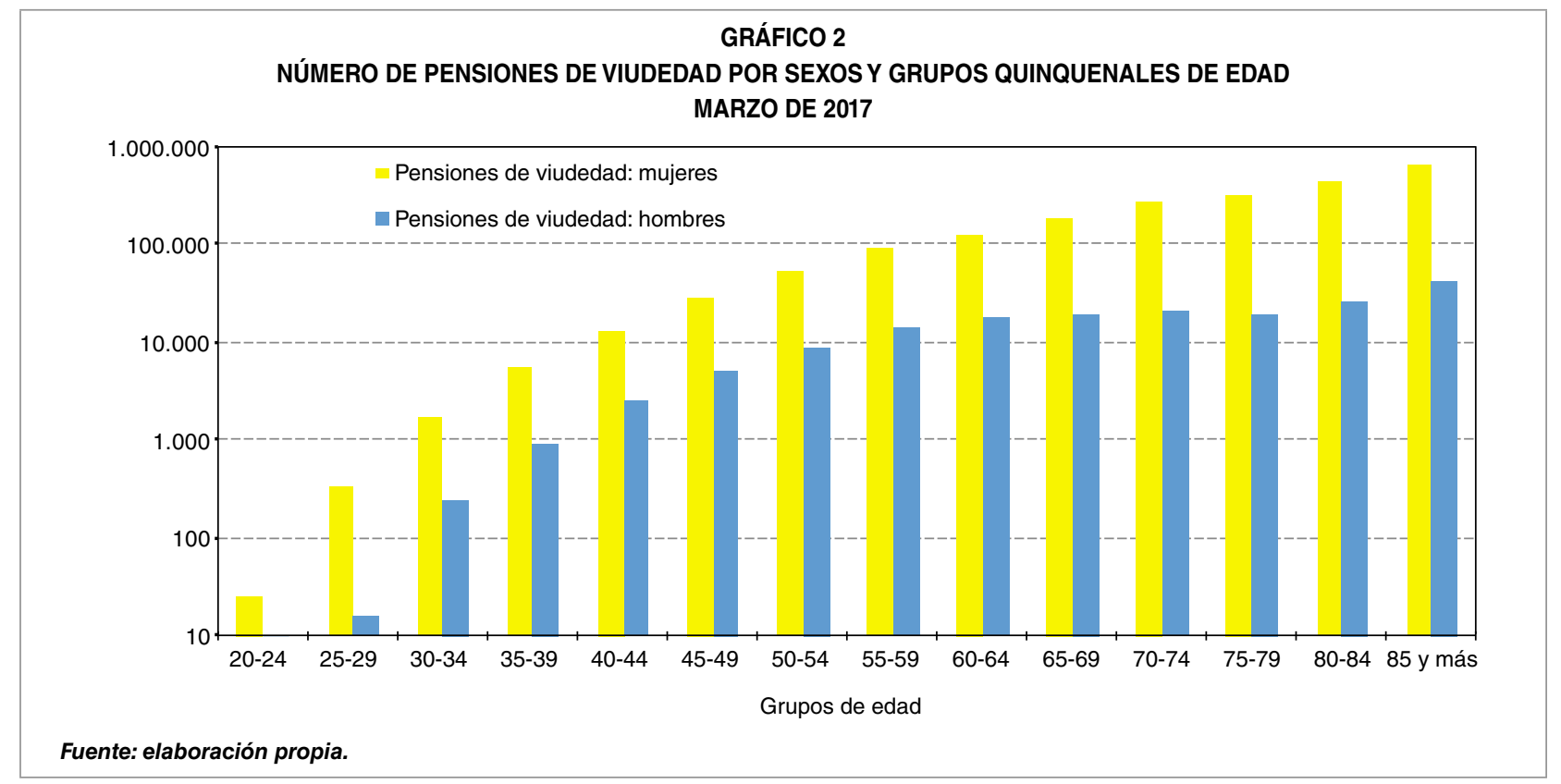

Gráfico 2, ya que en conjunto las pensiones de viudedad de los varones solo representan el 7,6 por 100 del total).

Sin embargo, para evitar duplicidades, en la estadística los pensionistas en que concurren las dos pensiones solo se computan en el epígrafe de la que tenga mayor cuantía, lo que implica que el 30 por 100 de quienes perciben una pensión de viudedad disfrutan al mismo tiempo de una pensión de incapacidad o jubilación. Esta situación afecta especialmente a las edades por encima de la edad legal de jubilación: así, mientras en el grupo de edades entre 55 y 59 años la concurrencia solo afecta al 7,6 por 100 de las pensiones, en el de 60-64 la cifra se eleva al 17,3 por 100 , para saltar al 44 por 100 , el 38,6 por 100 y el 32,8 por 100 en los grupos quinquenales subsiguientes, y al 30 por 100 en los mayores de 80 años, gradación que está relacionada obviamente con la evolución de las tasas históricas de actividad de las mujeres en las correspondientes cohortes de edad.

En nuestra modelización actuarial las pensiones de jubilación y de viudedad derivadas de un mismo sujeto causante se contemplan como un todo continuo, o sea, como un recurso imputable a la unidad familiar, compuesto de dos tramos: el de la pensión plena, mientras viven los dos cónyuges, y el de pensión de viudedad, que, según la nómina mensual del mes de abril de 2017, equivale en media para el conjunto del sistema al 60,9 por 100 de la pensión de jubilación (al 56,8 por 100 en el Régimen General). Por esta razón, la parte del tipo de cotización imputable conjuntamente a las pensiones de jubilación y viudedad equivale a la proporción que representa la suma del gasto total en estas dos clases de pensiones respecto al conjunto del gasto en pensiones. En abril de 2017 esta proporción asciende al 88,11 por 100 de la cotización total por contingencias comunes (28,3 por 100 ), de modo que la cotización imputable a las pensiones de jubilación y viudedad ascendería conjuntamente al 24,9346 por 100 , como se observa en el Cuadro 2 (mientras que computando solo la pensión de jubilación la proporción era del 70,6 por 100 y el tipo imputable, el 19,99 por 100, como sucedía en el Cuadro 1). 
CUADRO 2

EQUILIBRIO ACTUARIAL INERCIAL DEL SISTEMA DE PENSIONES DE JUBILACIÓN-VIUDEDAD CON AÑOS DE COTIZACIÓN Y ESPERANZA DE VIDA FIJOS

\begin{tabular}{|c|c|c|c|c|c|c|}
\hline \multicolumn{7}{|c|}{ Tipo de cotización para la pensión de jubilación-viudedad } \\
\hline FP & $24,9 \%$ & & & & & \\
\hline$i=0,01$ & 11,2 & & & & & \\
\hline$i=0,015$ & 12,3 & & & & & \\
\hline \multicolumn{7}{|c|}{ Ratio de reposición de la pensión de jubilación } \\
\hline$C P$ & $48,6 \%$ & $50,0 \%$ & $55,0 \%$ & $60,0 \%$ & $65,0 \%$ & $70,5 \%$ \\
\hline$i=0,01$ & 9,8 & 10,1 & 11,1 & 12,1 & 13,1 & 14,2 \\
\hline$i=0,015$ & 9,2 & 9,5 & 10,5 & 11,4 & 12,4 & 13,4 \\
\hline \multicolumn{7}{|c|}{ Equilibrio del fondo de pensiones de jubilación-viudedad } \\
\hline \multicolumn{7}{|l|}{ FP-CP } \\
\hline$i=0,01$ & 1,4 & 1,1 & 0,1 & $-0,9$ & $-1,9$ & $-3,0$ \\
\hline$i=0,015$ & 3,1 & 2,8 & 1,8 & 0,9 & $-0,1$ & $-1,1$ \\
\hline Proyección año & 2016-2022 & 2025 & 2033 & 2042 & 2050 & 2059 \\
\hline
\end{tabular}

El modelo aplicable a España simula que el capital conjunto de estas dos pensiones es el resultado de agregar al de la pensión de jubilación, ya estudiado, el requerido para abonar la pensión de viudedad durante el período $(m)$ en que el/la viudo/viuda sobrevive al cotizante causante. $Y$ el capital actualizado de esta pensión es: $C P V=m \cdot u \cdot \sigma \cdot w /(1+i)^{\eta+(m / 2)}$. El período $m$ se estima como la diferencia entre la edad media del pensionista de viudedad y la del pensionista de jubilación, situada en 2,14 años. El punto medio del período de percepción se sitúa, pues, a los 22,1 años de la edad de jubilación: $\eta+[m / 2]=21,03+1,07^{4}$. Finalmente, para tomar en consideración las pensiones de viudedad causadas antes de la edad de jubilación se aumenta la cifra estimada de CPV en un 20,9 por 100 , que es la ratio de la nómina de gasto en pensiones de viudedad con edades por debajo de 65 años respecto a la de los de 65 años y más.

\footnotetext{
4 Las edades medias de los pensionistas de viudedad y de jubilación en abril de 2017 eran 77,88 y 75,75 años, respectivamente. La ratio de pensiones de viudedad/jubilación (u), 0,609: http://www.seg-social. es/Internet_1/Estadistica/Est/Pensiones_y_pensionistas/Pensiones_ contributivas_en_vigor/Por_edades/index.htm
}

Bajo estos supuestos, el fondo de pensión acumulado a lo largo de la vida laboral representativa fluctuaría entre 11,2 y 12,3 salarios anuales en las dos hipótesis de crecimiento. En cambio, el capital necesario para financiar la pensión de jubilación más la de viudedad asociada a la misma se situaría actualmente entre 9,8 y 9,2 anualidades de salario, arrojando un superávit de 1,4 y 3,1 anualidades, respectivamente. En el escenario con menor tasa de crecimiento seguiría registrándose superávit hasta después de 2033 y el déficit se situaría en tres anualidades en 2059, mientras que en el escenario base el superávit se mantendría casi hasta 2050, y en 2059 aparecería un déficit de 1,1 veces el salario anual (que quedaría prácticamente anulado con un crecimiento de 1,75 por 100 y se convertiría en superávit de casi una anualidad con crecimiento del 2 por 100).

Finalmente, si tomásemos en consideración también las pensiones de orfandad y en favor de familiares, el tipo de cotización imputable se elevaría al 25,4 por 100 y el CPV corregido habría que aumentarlo todavía en un 9,9 por 100 (o sea, un 32,8 por 100 en total). Con ello, el $\triangleright$ 
fondo de pensiones acumulado aumentaría en dos décimas, pero el capital-pensión quedaría prácticamente igual o aumentaría en una o dos décimas, de modo que en el escenario base el superávit actual se situaría en 3,2 y solo en el horizonte de 2059 aparecería un déficit de una anualidad (alcanzándose el equilibrio con un crecimiento anual medio de 1,75 por 100).

Por todo lo cual cabe concluir que contemplado como una foto fija el sistema español de pensiones se diseñó de manera que en términos estáticos garantizaría razonablemente el equilibrio actuarial, ya que bajo el supuesto de un escenario de crecimiento bastante prudente el fondo de pensión teórico acumulado superaría con mucho al capital coste de la pensión y se mantendría en superávit prácticamente durante la primera mitad del siglo actual.

\section{La dinamización del modelo con esperanza de vida y carreras de cotización variables}

Sucede, sin embargo, que no se puede razonar solo en términos estáticos, y muy especialmente en lo que se refiere a la demografía. El primer aspecto a considerar para dinamizar nuestro modelo es el de la evolución de la

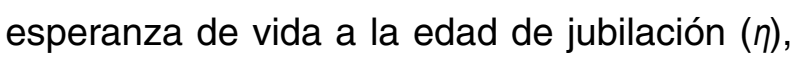
que, al introducir la variable tiempo, ya no puede tomarse como un parámetro, sino más bien como una variable exógena, que es la que determina, en primer lugar, la diferencia entre equidad actuarial intrageneracional y equidad intergeneracional, ya que si las distintas generaciones tienen diferentes esperanzas de vida (como viene ocurriendo y previsiblemente seguirá haciéndolo en el futuro), el supuesto de una $\eta$ constante en que se basan nuestros Cuadros 1 y 2 no se da, y la aportación y todos los cálculos deberían rehacerse tomando en consideración la evolución de la esperanza de vida a la edad de jubilación prevista para cada generación.

En el trabajo de Meneu, Devesa et al. (2016), por ejemplo, se estudian seis mecanismos automáticos de ajuste relacionados con la evolución de la esperanza de vida, asociando los parámetros del sistema a la proyección de esta última a lo largo del tiempo de modo que resulte neutral desde el punto de vista intergeneracional, el primero de los cuales consiste en adaptar la edad de jubilación a la evolución previsible de la esperanza de vida.

Aunque en nuestros Cuadros 1 y 2 los escenarios alternativos al actual no se referían directamente al tiempo, sí se tomaban como referencia ratios de reposición (entre 50 y 70,5 por 100) que se corresponden con la proyección lineal de las mismas entre 2025 y 20592060, por lo que conviene realizar ese mismo ejercicio con la esperanza de vida proyectada para esos años, a la edad de jubilación previsible tras la reforma de 2011.

Por esa razón, el Cuadro 3 se encabeza con dos filas que no figuraban en los cuadros anteriores: la primera registra la edad de jubilación prevista para esos años, con la salvedad de que - por razones que se explican más adelante- la prolongación de la edad establecida por la reforma de 2011 se ha extrapolado a partir de 2027, en que se alcanza la edad de 67 años, a razón de un aumento de un mes por cada año transcurrido (no dos como hasta entonces), de modo que la edad legal de jubilación se situaría en 70 años en 2063. En la segunda fila se escriben los pares de datos $n / \eta$ correspondientes a aquellos mismos años, suponiendo que el aumento en la edad legal de jubilación se traslada automáticamente a los años medios de cotización, y consignando $\triangleright$ 
CUADRO 3

EQUILIBRIO ACTUARIAL INERCIAL DEL SISTEMA DE PENSIONES DE JUBILACIÓNY VIUDEDAD CON AÑOS DE COTIZACIÓNY ESPERANZA DE VIDA VARIABLES

\begin{tabular}{|c|c|c|c|c|c|c|}
\hline $\begin{array}{l}\text { Edad jubilación } \\
n / \eta\end{array}$ & $\begin{array}{c}65,3 \\
37,2 / 20,7\end{array}$ & $\begin{array}{c}66,7 \\
38,6 / 20,7\end{array}$ & $\begin{array}{c}67,5 \\
39,4 / 21\end{array}$ & $\begin{array}{c}68,3 \\
40,1 / 21,4\end{array}$ & $\begin{array}{c}68,9 \\
40,8 / 20,8\end{array}$ & $\begin{array}{c}69,7 \\
41,6 / 22\end{array}$ \\
\hline \multicolumn{7}{|c|}{ Tipo de cotización para la pensión de jubilación-viudedad } \\
\hline$F P$ & $24,9 \%$ & $24,9 \%$ & $24,9 \%$ & $24,9 \%$ & $24,9 \%$ & $24,9 \%$ \\
\hline$i=0,01$ & 11,2 & 11,7 & 12,0 & 12,3 & 12,6 & 12,9 \\
\hline$i=0,015$ & 12,3 & 12,9 & 13,3 & 13,7 & 14,0 & 14,4 \\
\hline \multicolumn{7}{|c|}{ Ratio de reposición de la pensión de jubilación } \\
\hline CP & $48,6 \%$ & $50,0 \%$ & $55,0 \%$ & $60,0 \%$ & $65,0 \%$ & $70,5 \%$ \\
\hline$i=0,01$ & 9,7 & 9,9 & 11,1 & 12,3 & 13,0 & 14,7 \\
\hline$i=0,015$ & 9,2 & 9,4 & 10,5 & 11,6 & 12,3 & 13,9 \\
\hline \multicolumn{7}{|c|}{ Equilibrio del fondo de pensiones de jubilación-viudedad } \\
\hline \multicolumn{7}{|l|}{ FP-CP } \\
\hline$i=0,01$ & 1,5 & 1,7 & 0,9 & 0,1 & $-0,4$ & $-1,9$ \\
\hline$i=0,015$ & 3,1 & 3,5 & 2,8 & 2,1 & 1,7 & 0,5 \\
\hline Proyección año & $2016-22$ & 2025 & 2033 & 2042 & 2052 & 2059 \\
\hline
\end{tabular}

la esperanza de vida a aquella edad de acuerdo con las proyecciones del INE ${ }^{5}$.

Puede observarse que hasta 2033 la reforma de 2011 garantiza prácticamente que el aumento previsible de la esperanza de vida queda neutralizado por la elevación de la edad de jubilación, de modo que la esperanza media de los años en que se percibe la pensión de jubilación apenas varía (mientras que de haberse mantenido fija la edad de jubilación esa cifra habría aumentado en dos años). El supuesto de prórroga de esa medida a partir de 2027 supondría que en 2059 la esperanza media de percepción de la pensión de jubilación aumentaría en 1,3 años con respecto a la actualidad (mientras que sin la reforma de 2011 y su prórroga el aumento habría sido de 5 años, y sin la prórroga, de 3,6 años).

En el Cuadro 3 se comprueba que la reforma de 2011, al neutralizar el impacto del

5 Descargadas de: $h t t p: / / w w w . i n e . e s / j a x i / T a b / a . h t m ? p a t h=/ t 20 / p 278 /$ p04/e2//0/\&file=01002.px. Para edad fraccionaria la cifra se pondera por el número de meses en los dos años enteros que la delimitan. aumento de la esperanza de vida, elevando al mismo tiempo la edad legal de jubilación (bajo la hipótesis de que su aumento se traslada íntegro al período de cotización), conduce a que el grado de equilibrio actuarial que aparece en este cuadro mejore ampliamente la que aparecía en el Cuadro 2, ya que en este caso solo se registraría déficit al final del período considerado (inferior a dos anualidades) si el crecimiento fuera del 1 por 100, mientras que con crecimiento medio del 1,5 por 100 el superávit al final del período resultaría de media anualidad. El equilibrio se reforzaría todavía en dos décimas en el caso de computar también las otras pensiones familiares, imputando igualmente las cotizaciones correspondientes. Por esos mismos motivos, en tal caso la evolución de la esperanza de vida no tendría tampoco efectos sobre la equidad intergeneracional.

Todos estos cálculos y buena parte de los razonamientos se mantendrían prácticamente idénticos si en lugar de la pensión de jubilación del conjunto del sistema hubiéramos $\triangleright$ 
CUADRO 4

EQUILIBRIO ACTUARIAL INERCIAL DEL SISTEMA DE PENSIONES DE JUBILACIÓN, VIUDEDADY OTRAS PENSIONES FAMILIARES: RÉGIMEN GENERAL (CON AÑOS DE COTIZACIÓNY ESPERANZA DE VIDA VARIABLES)

\begin{tabular}{|c|c|c|c|c|c|c|}
\hline $\begin{array}{l}\text { Edad jubilación } \\
n / \eta\end{array}$ & $\begin{array}{c}65,5 \\
37,4 / 20,9\end{array}$ & $\begin{array}{c}67 \\
38,9 / 20,7\end{array}$ & $\begin{array}{c}67,75 \\
39,6 / 21,1\end{array}$ & $\begin{array}{c}68,50 \\
40,4 / 21,5\end{array}$ & $\begin{array}{c}69,2 \\
41,1 / 21,6\end{array}$ & $\begin{array}{c}69,9 \\
41,7 / 22\end{array}$ \\
\hline \multicolumn{7}{|c|}{ Tipo de cotización de pensión de jubilación-viudedad } \\
\hline$F P$ & $25,4 \%$ & $25,4 \%$ & $25,4 \%$ & $25,4 \%$ & $25,4 \%$ & $25,4 \%$ \\
\hline$i=0,01$ & 11,5 & 12,0 & 12,3 & 12,6 & 12,8 & 13,1 \\
\hline \multirow[t]{2}{*}{$i=0,015$} & 12,6 & 13,3 & 13,6 & 14,0 & 14,3 & 14,6 \\
\hline & \multicolumn{6}{|c|}{ Ratio de reposición de la pensión de jubilación } \\
\hline$C P$ & $55,0 \%$ & $60,0 \%$ & $65,0 \%$ & $70,0 \%$ & $75,0 \%$ & $80,0 \%$ \\
\hline$i=0,01$ & 11,0 & 11,9 & 13,2 & 14,5 & 15,4 & 16,8 \\
\hline \multirow[t]{2}{*}{$i=0,015$} & 10,4 & 11,3 & 12,4 & 13,7 & 14,6 & 15,8 \\
\hline & \multicolumn{6}{|c|}{ Equilibrio del fondo de pensiones de jubilación-viudedad } \\
\hline \multicolumn{7}{|l|}{ FP-CP } \\
\hline$i=0,01$ & 0,4 & 0,1 & $-0,9$ & $-1,9$ & $-2,6$ & $-3,7$ \\
\hline$i=0,015$ & 2,2 & 2,0 & 1,2 & 0,3 & $-0,3$ & $-1,2$ \\
\hline Proyección año & 2016-2018 & 2027 & 2036 & 2045 & 2053 & 2062 \\
\hline
\end{tabular}

utilizado para las proyecciones la pensión de jubilación del Régimen General, que es precisamente el punto de encuentro hacia el que se dirige el conjunto del sistema español de pensiones. En este caso, el punto de partida para 2016-2018 sería una ratio de reposición del 55 por 100, y los sucesivos tramos, desde el 60 al 80 por 100, se recorrerían con dos o tres años de retraso, como se observa en el Cuadro 4. Habría que variar también las cifras relativas a la ratio pensión de viudedad/ pensión de jubilación $(0,568$ en este caso vs. $0,609)$, la diferencia de años de supervivencia $(2,6$ vs. 2,14$)$ y la relación entre la nómina de las pensiones de viudedad de los menores de 65 y la de los mayores de esa edad $(0,09$ vs. 0,21 ), ya que las restantes ratios apenas se diferencian. Incluyendo el conjunto de pensiones familiares (con viudedad y supervivencia a todas las edades, cuyo índice de corrección sería del 20 por 100 , en lugar del 32 por 100 en el conjunto del sistema), los resultados del ejercicio se presentan en el Cuadro 4, según el cual, con un crecimiento del 1,5 por 100 el déficit aparecería por primera vez en $2053(-0,3)$ y se elevaría a -1,2 por 100 en 2062. En cambio, bajo el supuesto de crecimiento medio anual del 1,75 por 100 (crecimiento esperado en la UE para el cuatrienio actual), 2061 seguiría registrando un ligero superávit, lo que corrobora la idea de que el grado de sostenibilidad del sistema de pensiones depende críticamente del crecimiento ${ }^{6}$.

\section{El dudoso equilibrio actuarial cuando se calculan las ratios de reposición con respecto al coste salarial ordinario}

Hasta aquí las ratios de reposición pensión/salario empleadas en el trabajo se han $\triangleright$

\footnotetext{
6 Con crecimiento de 1,5 por 100 estos desequilibrios serían entre tres y cuatro décimas superiores si solo se contemplasen las pensiones de jubilación y viudedad (como se hacía en el Cuadro 3). En tal caso, para el supuesto de un crecimiento medio anual del 1,75 por 100 el déficit de 2061 se situaría en 0,3 anualidades.
} 
CUADRO 5

EQUILIBRIO ACTUARIAL INERCIAL DEL SISTEMA DE PENSIONES (DE JUBILACIÓN Y VIUDEDAD) CON RATIO DE REPOSICIÓN «PENSIÓN MENSUAL DE JUBILACIÓN DEL SISTEMA»/“COSTE SALARIAL ORDINARIO POR TRABAJADOR Y MES» (CSOTMTS)

\begin{tabular}{|c|c|c|c|c|c|c|}
\hline $\begin{array}{l}\text { Edad jubilación } \\
n / \eta\end{array}$ & $\begin{array}{c}65,5 \\
37,4 / 20,9\end{array}$ & $\begin{array}{c}66,7 \\
38,5 / 20,7\end{array}$ & $\begin{array}{c}67,4 \\
39,3 / 20,9\end{array}$ & $\begin{array}{c}68,1 \\
40 / 21,3\end{array}$ & $\begin{array}{c}68,7 \\
40,6 / 21,6\end{array}$ & $\begin{array}{c}69,3 \\
41,1 / 21,8\end{array}$ \\
\hline \multicolumn{7}{|c|}{ Tipo de cotización para la pensión de jubilación-viudedad } \\
\hline FP & $24,9 \%$ & $24,9 \%$ & $24,9 \%$ & $24,9 \%$ & $24,9 \%$ & $24,9 \%$ \\
\hline$i=0,01$ & 11,2 & 11,7 & 11,9 & 12,2 & 12,4 & 12,6 \\
\hline$i=0,015$ & 12,4 & 12,9 & 13,2 & 13,5 & 13,8 & 14,0 \\
\hline$i=0,0175$ & 13,0 & 13,6 & 13,9 & 14,3 & 14,5 & 14,8 \\
\hline \multicolumn{7}{|c|}{ Ratio de reposición de la pensión de jubilación } \\
\hline$C P$ & $60,0 \%$ & $65,0 \%$ & $70,0 \%$ & $75,0 \%$ & $80,0 \%$ & $85,0 \%$ \\
\hline$i=0,01$ & 12,0 & 12,9 & 14,0 & 15,3 & 16,5 & 17,6 \\
\hline$i=0,015$ & 11,4 & 12,2 & 13,3 & 14,4 & 15,5 & 16,6 \\
\hline$i=0,0175$ & 11,1 & 11,9 & 13,0 & 14,0 & 15,1 & 16,1 \\
\hline \multicolumn{7}{|c|}{ Equilibrio del fondo de pensiones de jubilación-viudedad } \\
\hline \multicolumn{7}{|l|}{ FP-CP } \\
\hline$i=0,01$ & $-0,8$ & $-1,3$ & $-2,1$ & $-3,1$ & $-4,1$ & $-5,0$ \\
\hline$i=0,015$ & 1,0 & 0,6 & $-0,1$ & $-0,9$ & $-1,8$ & $-2,5$ \\
\hline$i=0,0175$ & 2,0 & 1,6 & 0,9 & 0,2 & $-0,6$ & $-1,3$ \\
\hline Proyección año & 2018 & 2025 & 2032 & 2040 & 2047 & 2054 \\
\hline
\end{tabular}

calculado a partir de las series de pensiones anuales y de coste laboral total anual, concepto próximo al de remuneración de asalariados de Contabilidad Nacional, que incluye tanto sueldos ysalarios como cotizaciones sociales y otros conceptos de coste laboral. Sin embargo, la ratio de reposición a la que se refiere la normativa de pensiones se calcula con respecto a la base reguladora de la cotización, concepto que -aunque no resulte por completo coincidente, dados los límites inferior y superior de la base - puede guardar una mayor relación con el denominado "coste salarial ordinario por trabajador y mes» 7 , relacionándolo con la pensión mensual (percibiéndose en ambos casos catorce pagas anuales).

\footnotetext{
7 Concepto muy próximo a lo que generalmente se denomina «el salario español». En el tercer trimestre de 2016 el CSOTMTS era de 1.636 euros al mes, y coincide con la media del sueldo medio español, según las comparaciones internacionales que realiza Adecco (cuando la media de la UE-28 era 1.934 euros).
}

En el Cuadro 5 se han reestimado los cálculos y las proyecciones que se hacían en el Cuadro 3. En el mismo se observa que la proyección de las ratios de reposición bajo tales supuestos anticipa considerablemente las fechas a las que se alcanzan los tramos entre el 60 y el 85 por 100 durante el período 20182054. Con los nuevos cálculos sobre edades de jubilación, años de cotización y esperanza de vida (prorrogando la ley de 2011), los resultados del ejercicio actuarial indican que con un crecimiento del 1 por 100 el fondo nocional acumulado para la pensión incurriría en déficit desde el primer momento y alcanzaría un máximo de cinco anualidades de infradotación en 2054. Con un crecimiento medio del 1,5 por 100 el déficit aparecería en 2032 y al final del período equivaldría a la mitad del anterior. Tan solo bajo el escenario ultraoptimista de un crecimiento medio del 1,75 por 100 la aparición del déficit se $\triangle$ 
CUADRO 6

EQUILIBRIO ACTUARIAL INERCIAL DEL SISTEMA DE PENSIONES (DE JUBILACIÓN, VIUDEDAD Y FAMILIARES) CON RATIO DE REPOSICIÓN «PENSIÓN MENSUAL DE JUBILACIÓN DEL RÉGIMEN GENERAL»/«COSTE SALARIAL» (CSOTMTS)

\begin{tabular}{|c|c|c|c|c|c|}
\hline $\begin{array}{l}\text { Edad jubilación } \\
n / \eta\end{array}$ & $\begin{array}{c}65,3 \\
37,1 / 20,7\end{array}$ & $\begin{array}{c}66,2 \\
38,1 / 20,8\end{array}$ & $\begin{array}{c}67,2 \\
39,1 / 20,8\end{array}$ & $\begin{array}{c}67,7 \\
39,6 / 21,1 / 21,5\end{array}$ & $\begin{array}{c}68,3 \\
40,1 / 21,4\end{array}$ \\
\hline \multicolumn{6}{|c|}{ Tipo de cotización para la pensión de jubilación-viudedad: $(\tau)$} \\
\hline FP & $25,4 \%$ & $25,4 \%$ & $25,4 \%$ & $25,4 \%$ & $25,4 \%$ \\
\hline$i=0,01$ & 11,4 & 11,7 & 12,1 & 12,3 & 12,5 \\
\hline$i=0,015$ & 12,5 & 12,9 & 13,4 & 13,6 & 13,9 \\
\hline$i=0,0175$ & 13,1 & 13,6 & 14,1 & 14,3 & 14,6 \\
\hline \multicolumn{6}{|c|}{ Ratio de reposición de la pensión de jubilación } \\
\hline CP & $70,0 \%$ & $75,0 \%$ & $80,0 \%$ & $85,0 \%$ & $90,0 \%$ \\
\hline$i=0,01$ & 14,0 & 15,1 & 16,1 & 17,3 & 18,5 \\
\hline$i=0,015$ & 13,3 & 14,3 & 15,2 & 16,3 & 17,5 \\
\hline$i=0,0175$ & 12,9 & 13,9 & 14,8 & 15,9 & 17,0 \\
\hline \multicolumn{6}{|c|}{ Equilibrio del fondo de pensiones de jubilación-viudedad } \\
\hline \multicolumn{6}{|l|}{$F P-C P$} \\
\hline$i=0,01$ & $-2,7$ & $-3,4$ & $-4,0$ & $-5,0$ & $-6,0$ \\
\hline$i=0,015$ & $-0,8$ & $-1,3$ & $-1,8$ & $-2,7$ & $-3,6$ \\
\hline$i=0,0175$ & 0,2 & $-0,3$ & $-0,7$ & $-1,6$ & $-2,4$ \\
\hline Proyección año & 2015 & 2022 & 2029 & 2035 & 2042 \\
\hline Fuente: elaboración & & & & & \\
\hline
\end{tabular}

retrasaría hasta 2047 (y al situarnos en 2054 se reduciría a la mitad del registrado en el escenario anterior).

Pero incluso en el supuesto de crecimiento más optimista $(1,75$ por 100$)$ el equilibrio actuarial del sistema español de pensiones quiebra cuando se considera el caso del Régimen General y se emplean ratios de reposición de la pensión mensual con respecto al coste salarial ordinario, como se observa en el Cuadro 6 (que en este caso contempla el conjunto de las pensiones de jubilación, viudedad y familiares, en correspondencia con lo que se hacía en el Cuadro 4). En el trabajo anterior sobre el sistema español de pensiones (Cuaderno de Documentación n. - 109) esta ratio de reposición ya se situaba en el 72,6 por 100 en 2016 (en términos de tendencia de largo plazo, el umbral del 70 por 100 se superó en 2015), y la proyección la hace aumentar en cinco puntos porcentuales cada siete años, para alcanzar el 90 por 100 en 2042, cifra que venía siendo considerada como el techo, de acuerdo con la regulación existente, dado el nivel de inflación definido como normal, si bien en tiempos de inflación infranormal el umbral se estaría desbordando -lo que debe considerarse excepcional y no adoptarse como norma para nuestra proyección-8.

En cualquier caso, el Cuadro 6 indica claramente que en el Régimen General (que es el punto de fuga para el conjunto del sistema) $\triangleright$

\footnotetext{
8 Considerando solo las nuevas altas de jubilación, el máximo responsable de la Seguridad Social declaró en abril que la tasa actual de sustitución (o reemplazo) del Régimen General es de 77,8 por 100 , y que llegará hasta el 94,3 por 100: http://cincodias.elpais.com/ cincodias/2017/04/25/midinero/1493129398_515693.html.También: http:// www.abc.es/economia/abci-empleo-afirma-relacion-entre-pension-ysalario-deberia-mas-realista-201704251529_noticia.html. En la proyección de Paxot et al. (2017, Tabla 1), en ausencia de las reformas de 20112013 , la ratio de reposición alcanzaría el 87,3 por 100 en 2060. Para la Comisión Europea (2016), la ratio de reposición teórica en 2053 para una carrera completa con ingresos medios será 86,8 por 100 (mientras que en 2013 habría sido 96,2 por 100).
} 
la equidad actuarial intrageneracional ${ }^{9}$ quedaría rota antes de 2022 incluso en el escenario de crecimiento considerado como ultraoptimista $(1,75$ por 100$)$, en que el déficit de provisiones ascendería a 2,4 anualidades salariales en 2042. En el caso más pesimista este déficit se habría sobrepasado con creces ya en 2015 y llegaría a seis anualidades dentro de 25 años. Solo con un crecimiento medio anual superior al 2,2 por 100 podría alcanzarse el equilibrio actuarial (lo que se aproxima a las estimaciones de Brío et al., 2016). En el contexto actualmente previsible, marcado por el choque traumático experimentado por las expectativas como consecuencia de la Gran Recesión ${ }^{10}$, este escenario dista mucho de las proyecciones de consenso, por lo que parece evidente que las ratios de reposición vigentes deben corregirse profundamente, solo para alcanzar la equidad actuarial intrageneracional.

\section{Equidad actuarial intrageneracional y equidad intergeneracional: la ratio de capacidad como factor determinante}

Ahora bien, incluso en los escenarios más optimistas contemplados hasta ahora, por contraposición a lo que habría sucedido si nuestro sistema de pensiones fuera de capitalización -en cuyo caso el fondo acumulado para la pensión se habría encontrado depositado bajo alguna modalidad de colocación y produciría

\footnotetext{
9 Se trata de una equidad potencial, considerando a cada cohorte como un todo, pese a la falta de equidad en el trato recibido por sus distintos componentes, estudiada por Jimeno (2003). Las reformas necesarias para mejorar la equidad en el seno de cada generación quedan fuera del alcance de este trabajo.

10 En el modelo de ciclo económico impulsado por las creencias de Kozlowski et al. (2015), el shock traumático consistente en la evidencia sobre la fragilidad del sistema financiero resulta imborrable, por lo que pesa como una losa sobre las expectativas y deprime la inversión, el empleo y la producción de manera persistente.
}

un cierto rendimiento (aunque sometido al riesgo del mercado) - , en un sistema de reparto (PAYGO) como el vigente son las sucesivas generaciones las que se encargan de «devolver» aquel fondo convertido en anualidades (a cuyo valor actual la OCDE denomina pension wealth $)^{11}$, ya que las pensiones se abonan con la recaudación de las cotizaciones corrientes.

Esto es, por mucho que las generaciones que acceden en un momento dado a la situación de pensionistas hubieran acumulado «nocionalmente» (o sea, en función de los cálculos actuariales estudiados en los dos epígrafes anteriores) a lo largo de su vida laboral un fondo-pensión suficiente para sufragar las anualidades de sus pensiones, estas no podrían hacerse efectivas en términos estrictamente contributivos si los ingresos anuales del sistema resultaran ser inferiores a la nómina anual de pensiones, de modo que en un sistema de reparto la equidad intergeneracional importa tanto o más que la equidad actuarial intrageneracional.

El modo más sencillo para analizar el grado de equidad intergeneracional $-\mathrm{y}$, por lo tanto, la sostenibilidad contributiva del sistema a lo largo del tiempo- es la ecuación [3] del modelo estudiado en Espina (2017a) ${ }^{12}$, transformada en ecuación dinámica:

$$
\left[3^{\prime}\right] E_{t} / P_{t}=\left(p^{*} / w^{\star}\right) \cdot\left(1 / T_{t}\right)=\sigma^{*} \cdot\left(1 / T_{t}\right)
$$

Esta ecuación refleja la restricción presupuestaria intertemporal de todo sistema de $\square$

\footnotetext{
11 Los primeros cálculos, realizados en OECD (2005, p. 67), arrojaban una «riqueza de pensión» media para la OCDE-30 de 8,7 ingresos anuales medios en el caso de los hombres y 10,2 en el de las mujeres (11,3 y 13,2 para España). Los últimos, disponibles en OECD (2015, p. 149), son 9,5/10,8 para OCDE-34 (14,6/17,2 para España). En ambos casos el tipo de interés (discount rate) para calcular el valor actual de las pensiones es 2 por 100. Los niveles españoles se sitúan en tercer lugar dentro del área y cubren el espectro completo de los cálculos realizados hasta ahora en este trabajo.

12 Pro memoria: [3] $E \cdot W \cdot \tau=P \cdot p$, siendo $E$ el número de empleadoscotizantes, $P$ el número de pensionistas, $p$ la pensión media y $\tau$ el tipo de cotización en cada momento del tiempo.
} 


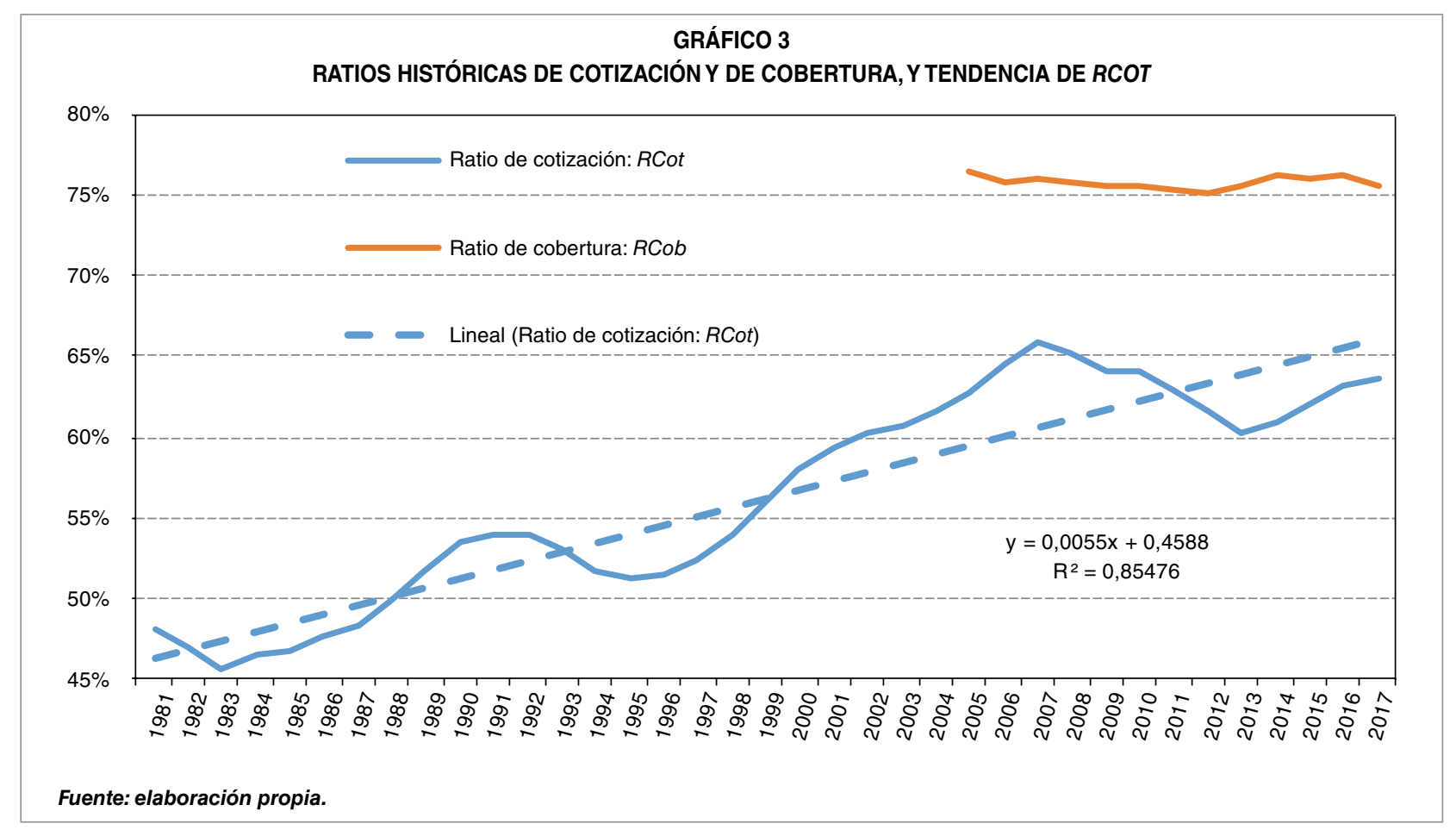

reparto con prestaciones o beneficios definidos (PAYGO-DB) y permite simular los diferentes escenarios, analizar la probabilidad de aparición de eventuales desequilibrios y estudiar los correspondientes procesos de ajuste ${ }^{13}$.

El primer miembro de [3'] es la ratio de empleados/pensionistas, o, más concretamente, de cotizantes/pensionistas, que depende a su vez de tres variables: a) la relación entre la población en edad de trabajar $(P e T)$ y la población en edad de jubilación $(P e J)$, a la que denominaremos ratio de capacidad demográfica $\left.(R C D=P e T / P e J)^{14} ; b\right)$ la relación entre el número de cotizantes ${ }^{15}$ y la $P e T$, a la que

\footnotetext{
13 Todas las variables de [3'] llevan subíndice $t$ del año en que se abona la pensión, con la excepción de $\sigma^{\star}=p^{\star} / W^{\star}$, que es la ratio de reposición pensión/salario, que queda establecida en el año de la jubilación pero sigue después las reglas específicas de revalorización, por lo que varía a lo largo del tiempo de percepción de la pensión. Solo en el caso de que la revalorización de la pensión fuera igual al crecimiento del salario, $\sigma^{*}$, permanecería constante a lo largo del tiempo. En caso contrario, $\sigma_{t}=p_{t} / w_{t}$ se comportaría como variable exógena.

${ }_{14}$ Nótese que la relación engloba todos los factores que influyen sobre el tamaño relativo de los dos grupos, incluída la evolución de la esperanza de vida, entre otros.

15 No solo empleados, pues los beneficiarios de la prestación por desempleo también cotizan, de modo que la cifra es más próxima
}

denominaremos ratio de cotización $(R \operatorname{Cot}=A$ ) $P e T)$, y c) la relación entre el número de pensionistas y la $P e J$, a la que denominaremos ratio de cobertura $(R C o b=P / P e J)$. La relación entre las tres ratios es:

$$
\left[3^{\prime \prime}\right]^{16} E_{t} / P_{t}=R C D_{t}^{*} R \operatorname{Cot}_{t} / R \operatorname{Cob}_{t}
$$

El Gráfico 3 representa las series de $\operatorname{RCot}^{17}$ y $R C o b^{18}$ para los años en que se dispone de datos homogéneos. Puede observarse que la evolución de la ratio de cotización es extraordinariamente sensible al ciclo económico (con mínimos temporales en 1983, 1995 y 2013), pero al mismo tiempo señala una fuerte $\square$

\footnotetext{
a la de activos (A), por lo que una proxy de RCot sería la tasa de actividad.

16 Ya que $E_{t} / P_{t}=E_{t} / P e T_{t}: P_{t} / P e T_{t} ;$ a su vez, $P_{t} / P e T_{t}=P_{t} / P e J_{t}$ : $P e T_{t}+/ P e J_{t}=R C o b_{t} / R C D_{t}$, de modo que denominando $R C^{t} t_{t}$ a $E_{t} / \mathrm{PeT}_{t}$ se obtiene [3"].

17 La serie $R C$ cot se construye por cociente entre la suma de las series BDSICE «190.000» (afiliados en alta) y «182.500» (total de perceptores de prestaciones económicas por desempleo) y la de población total entre 15 y 64 años tomada de la base de datos del INE.

18 Cociente entre el número de pensionistas con 65 y más años y la población total en esos mismos grupos de edad.
} 


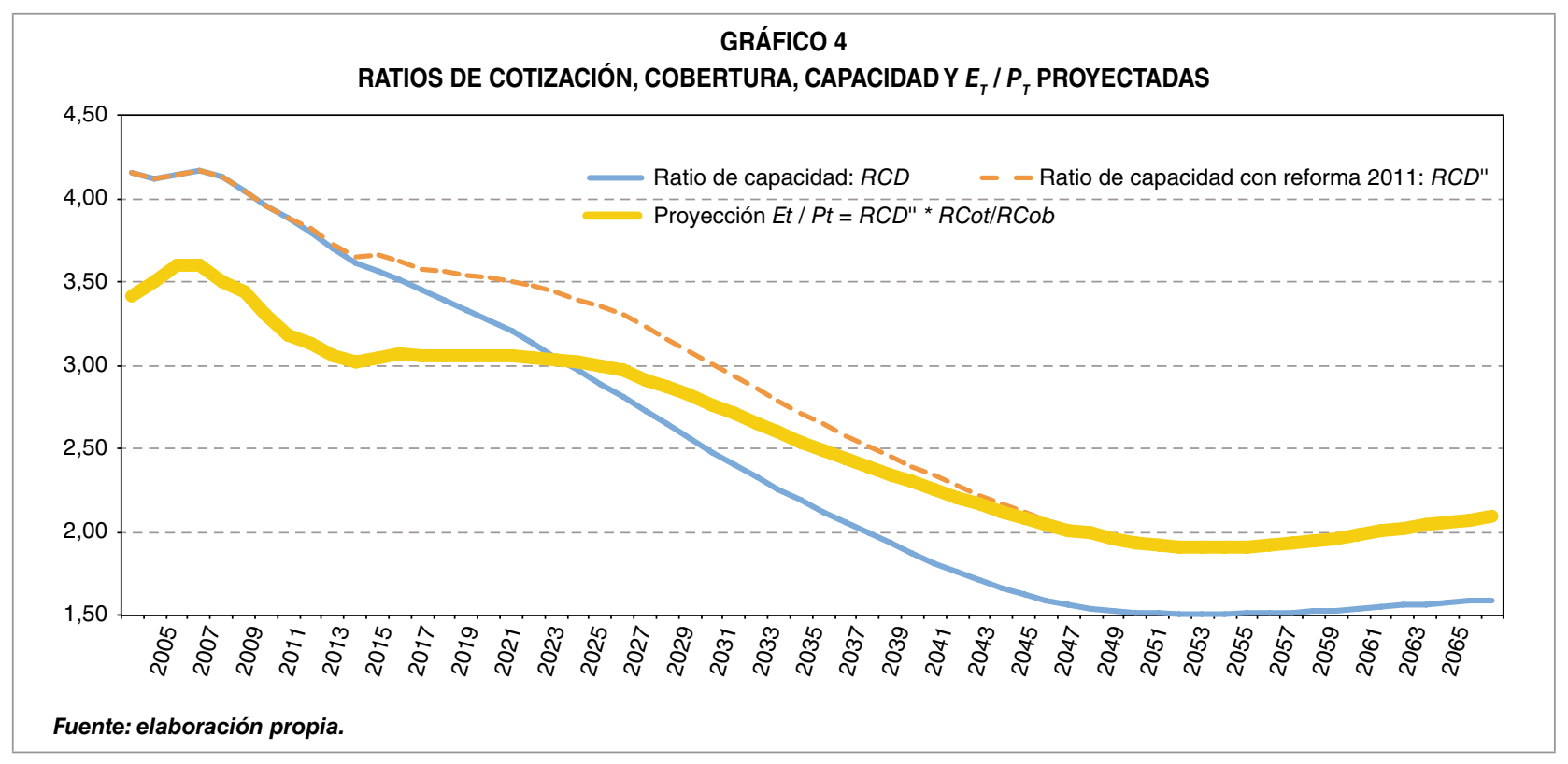

tendencia lineal, que aumenta a un ritmo de 5,5 puntos porcentuales cada diez años, derivada obviamente de la tendencia histórica hacia el crecimiento de la tasa de actividad, que ha resultado ininterrumpida desde la aparición de la EPA. En la proyección hacia adelante mantendremos aquel coeficiente hasta alcanzar el nivel máximo de las tasas de actividad registradas actualmente en la UE (caso de Suecia, con el 81,7 por 100), de modo que nuestra $R C o t$ solo se estabiliza en 2048 , en que alcanza el nivel 0,8163$)^{19}$.

La variable $R C o b$, o tasa de cobertura de las pensiones, es obviamente un derivado de la anterior con un cierto nivel de retardo temporal, ya que el derecho a pensión se alcanza a través de la cotización a lo largo de la vida laboral y, en el límite, cuando el sistema de pensiones se encuentre completamente maduro, se igualará con RCot. En el Gráfico 3, la serie disponible ya tiene un perfil muy estable, aunque el período

\footnotetext{
19 En la proyección de Sánchez (2014) esta tasa se sitúa en el 83 por 100. En el Ageing Report de la Comisión Europea (2015a) la tasa alcanza su máximo en 2045 (79,7 por 100 para la población 15-64; 85,1 por 100 para 20-64).
}

para el que disponemos de datos es muy limitado. En nuestra proyección, supondremos que la equiparación se produce precisamente en el momento en que RCot alcanza su máximo, en 2048, interpolando los datos desde 2017.

El Gráfico 4 y el Cuadro 7 presentan los resultados de nuestra proyección. La línea $R C D$ corresponde a la ratio población 15-64/ población $\geq 65$ de la base de datos del INE, históricos y proyectados. En la variable denominada $R C D$ " se ha aplicado la reforma de la edad de jubilación adoptada en 2011, prorrogándola desde 2027 (aumentando un mes por año transcurrido hasta alcanzar los 70 años en 2063) y aplicando las nuevas edades como divisoria entre los grupos de edad PeT" y PeJ".

En la parte superior del Cuadro 7 figura una síntesis por decenios de las series $P e T, P e J$, $P$, y $R C D$, que se deducen de la proyección demográfica del INE para el período 2016-2066 y de la ratio de cobertura proyectada (incluyendo también las cifras de los años extremos de la proyección), bajo el supuesto de que se hubiera mantenido la edad de jubilación fija a los 65 años. En la quinta fila se observa que en $\triangleright$ 
tal caso la ratio de capacidad demográfica se reduciría en un 60 por 100 hasta 2050 y algo menos a lo largo del período proyectado (las cifras de poblaciones se expresan en millones).

En la parte inferior del cuadro se reestiman todas las cifras demográficas y de poblaciones llevando la divisoria de los dos grandes grupos de edad a la nueva edad de jubilación derivada de la reforma de 2011 (prorrogándola a partir de 2027, como ya se ha dicho). Además, se incorporan las extrapolaciones de las ratios $R C o t$ y $R C o b$ ya comentadas. Puede observarse que la caída de la RCD" es muy inferior (un 45 por 100 a lo largo del período proyectado). Finalmente, el cálculo de $E_{t} / P_{t}$, de acuerdo con [3"] arroja un resultado según el cual a lo largo de los próximos cincuenta años la capacidad de financiación del sistema contributivo de pensiones se reducirá en un 31,3 por 100 (con un descenso máximo del 36,3 por 100 en 2050). En el cuadro se observa también que el número de pensionistas con edades por encima de la edad legal de jubilación que arroja este ejercicio pasaría de 6,5 millones en 2016 a 9,7 millones en 2066, con un crecimiento del 49 por 100 (mientras que en ausencia de prolongación de la edad de jubilación, con la misma ratio de cobertura se situaría en 11,6 millones, creciendo un 75 por 100). A su vez, la población cotizante alcanzaría un máximo en 2040, con un crecimiento del 10 por 100 respecto a 2016, pasando a una cifra solo un 2 por 100 superior a la actual en 2066 (mientras que con edad de jubilación fija disminuiría en 1,2 millones).

En todo caso, de acuerdo con el segundo miembro de [3'], tal desequilibrio solo podría corregirse reduciendo en aquella misma proporción la ratio de reposición pensión/salario $\left(\sigma^{*}\right)$, elevando el tipo de cotización $(\tau)$, o mediante una combinación proporcional de una y otra medida. La primera haría recaer todo el ajuste sobre las generaciones inactivas, pero resultaría equitativa desde la perspectiva $\triangle$

CUADRO 7

RATIOS DE COTIZACIÓN, COBERTURA, CAPACIDADY $E_{T} / P_{T}$ PROYECTADAS

\begin{tabular}{|c|c|c|c|c|c|c|c|c|}
\hline & 2010 & 2016 & 2020 & 2030 & 2040 & 2050 & 2060 & 2066 \\
\hline \multicolumn{9}{|l|}{$E J=65$ años } \\
\hline$P e T(E J 65)$ & 32,15 & 30,91 & 30,89 & 29,39 & 26,36 & 23,71 & 22,98 & 22,56 \\
\hline PeJ (EJ 65) & 7,93 & 8,66 & 9,27 & 11,46 & 14,07 & 15,61 & 14,89 & 14,19 \\
\hline$P e T_{\star} R \operatorname{Cot}=E_{t}$ & 20,62 & 19,62 & 20,29 & 20,92 & 20,21 & 19,35 & 18,76 & 18,42 \\
\hline$P e J^{\prime}{ }^{\prime} R C o b=P_{t}$ & 5,99 & 6,61 & 7,05 & 8,94 & 11,24 & 12,74 & 12,15 & 11,58 \\
\hline$R C D(E J 65)$ & 4,05 & 3,80 & 3,33 & 2,56 & 1,87 & 1,52 & 1,54 & 1,59 \\
\hline Dif 2016-66 $\left(E_{t} / P_{t}\right)$ & - & - & $-12,4 \%$ & $-32,6 \%$ & $-50,8 \%$ & $-60,1 \%$ & $-59,4 \%$ & $-58,2 \%$ \\
\hline EJ (Ley 27/2011...) & 65,00 & 65,33 & 65,83 & 67,25 & 68,08 & 68,92 & 69,75 & 70,00 \\
\hline$P e T^{\prime \prime}$ & 32,15 & 31,32 & 31,31 & 30,86 & 28,53 & 25,95 & 25,18 & 24,87 \\
\hline PeJ" & 7,93 & 8,55 & 8,84 & 9,99 & 11,90 & 13,37 & 12,69 & 11,88 \\
\hline$R C D ”$ & 4,05 & 3,80 & 3,54 & 3,09 & 2,40 & 1,94 & 1,98 & 2,09 \\
\hline$R \operatorname{Cot}$ & 0,64 & 0,63 & 0,66 & 0,71 & 0,77 & 0,82 & 0,82 & 0,82 \\
\hline$R C o b$ & 0,76 & 0,76 & 0,76 & 0,78 & 0,80 & 0,82 & 0,82 & 0,82 \\
\hline$P e T{ }^{*} R C o t=E_{t}$ & 20,62 & 19,88 & 20,56 & 21,97 & 21,88 & 21,19 & 20,56 & 20,30 \\
\hline$P e J "{ }_{*} R C o b=P_{t}$ & 5,99 & 6,52 & 6,73 & 7,79 & 9,51 & 10,91 & 10,36 & 9,70 \\
\hline$E{ }_{t} / P{ }_{t}$ & 3,44 & 3,05 & 3,06 & 2,82 & 2,30 & 1,94 & 1,98 & 2,09 \\
\hline$\Delta$ 2016-66 (E" / $\left.{ }_{t}^{\prime \prime}\right)$ & - & - & $0,25 \%$ & $-7,52 \%$ & $-24,55 \%$ & $-36,34 \%$ & $-34,92 \%$ & $-31,33 \%$ \\
\hline
\end{tabular}


intergeneracional, porque el mismo ajuste afectaría más tarde a las generaciones activas, al acceder a la jubilación. En cambio, la segunda medida recaería plenamente sobre las generaciones activas, no solo porque con ello se elevarían sus aportaciones (sin la menor esperanza de recuperar en el futuro lo aportado en forma de mayor pensión, acumulando al desequilibrio intergeneracional un desequilibrio actuarial intrageneracional muy superior), sino porque tal elevación repercutiría con seguridad sobre la capacidad de creación de empleo de la economía, generando una espiral de desequilibrios en la ratio $E_{t} / P_{t}$, cercenando la posibilidad de acumular derechos futuros de pensión para las generaciones activas que soportan el ajuste $^{20}$.

\section{La reforma de 2013 y la equidad intergeneracional}

Como es bien sabido, la reforma del sistema español de pensiones adoptada a través de la Ley 23/2013 introdujo un mecanismo de corrección de las pensiones con dos componentes: un «factor de sostenibilidad» (FS) —relacionado con el aumento de la esperanza de vida, solo aplicable a las nuevas altas en pensiones que se produzcan a partir del año 2019- y un nuevo «índice de revalorización» (IR), aplicable anualmente a todas las pensiones en vigor, sustituyendo al IPC como indicador de referencia.

La primera parte de esta reforma resulta cuando menos sorprendente porque la reforma

20 Debe tenerse en cuenta que del conjunto de países de la OCDE España era ya en 2014, después de Italia, el que tenía tipos de cotización más elevados (con el 28,3 por 100 y el 33 por 100, respectivamente). En ambos casos el tipo de cotización del empleador es muy similar (26,3 por 100 y 26,81 por 100 ), pero la cotización del trabajador asciende al 9,19 por 100 en Italia, mientras que en España se sitúa en el 4,7 por 100: OECD (2015), p. 177. de la Ley 27/2011 ya había acometido el problema del aumento en la esperanza de vida, prolongando la edad de jubilación hasta los 67 años paulatinamente entre 2011 y 2027 , y señalando que a partir de ese año se introduciría un factor de sostenibilidad, no bien definido, lo que parecía apuntar a que tal factor consistiría en prolongar la medida, reajustándola tras verificar que las esperanzas de vida proyectadas se habían cumplido efectivamente (o corrigiéndolas, si existieran desviaciones).

La propuesta era coherente, pues el aumento en la edad de jubilación ordinaria establecido hasta ese año funciona en realidad como un «factor de sostenibilidad», ya que, según las proyecciones demográficas del INE, la prolongación de la edad prevista hasta 2027 (acompañada del aumento consecuente en los períodos de cotización) hace que la esperanza de vida a las nuevas edades de jubilación se mantenga exactamente al mismo nivel de la esperanza existente en $2014^{21}$. De hecho, de las dos alternativas disponibles para contrarrestar el desequilibrio intergeneracional derivado del aumento de la esperanza de vida - aumentar la edad y los períodos exigidos de cotización, o disminuir la ratio de reposición- la mayoría de los países europeos han optado por la primera (Paxot et al., 2017), y esa es la principal recomendación de la Unión Europea.

La alternativa habría consistido en disminuir la ratio de reposición en relación con el avance de la esperanza, dando opción a completarla prolongando voluntariamente la edad efectiva. En realidad, esto último constituye una medida adicional de sostenibilidad, independiente de la anterior, como ya sucede en nueve Estados $\triangleright$

\footnotetext{
21 Año en que la esperanza media de vida a los 65 años fue de 20,7 años, que coincide exactamente con la esperanza proyectada por el INE a los 67 años en 2027 (mientras que ese año la esperanza a la edad de 65 habrá aumentado hasta 22,4 años, creciendo 1,7 años).
} 
de la UE, en donde el retraso voluntario de dos años en la edad efectiva de jubilación supone en media un aumento de cinco puntos porcentuales en la ratio de reposición de la pensión correspondiente al ingreso medio ${ }^{22}$.

Lo que no había hecho ningún país es acumular las dos medidas: aumentar la edad hasta neutralizar el avance de la esperanza y reducir la ratio apoyándose para esto último en un motivo que ya no existe (puesto que para quien se jubile dentro de diez años la esperanza de vida como pensionista es igual a la de quien se jubila hoy). Puede ser necesario modificar la ratio de reposición por razones de sostenibilidad - como ya hemos visto y desarrollaremos más adelante-, pero eso no tiene nada que ver con la esperanza de vida. Por esa razón, en las simulaciones que se realizan en este trabajo y en lo que sigue se hace abstracción del factor de sostenibilidad, suponiendo que la medida no llegará a aplicarse. En su lugar, se amplía la medida de retraso en la edad ordinaria de jubilación a partir de 2027, aunque reduciendo su velocidad a la mitad, por lo que la edad legal sería 68 años en 2039, 69 años en 2051 y 70 años en 2063.

De este modo, a la congelación de la esperanza de vida en jubilación que se producirá hasta 2027, de acuerdo con la Ley 23/2011 en su redacción vigente, le seguiría un período de 36 años en que el aumento de la esperanza de vida media en el grupo de edades entre 65 y 70 años - que es de cuatro años, según las proyecciones del INE- se distribuiría aproximadamente en razón de 2/3 para aumentar la edad laboral y $1 / 3$ para elevar la esperanza de vida en jubilación -que aumentaría en algo menos de 1,4 años-, guardando esta distribución parecida proporción a la ratio $E_{t}$ " / $P_{t}$ " proyectada para ese período en el Cuadro 7.

22 Véase Comisión Europea (2016), p. 9.
La segunda parte de la reforma de 2013 consiste en la adopción de un «índice de revalorización» anual (IR) para las pensiones vigentes definido por la ley de esta forma:

$$
I R_{t+1}=\check{g}_{I, t+1}-\check{g}_{p, t+1}-\check{g}_{s, t+1}+\alpha \frac{I_{t+1}^{*}-G_{t+1}^{*}}{G_{t+1}^{*}}
$$

Por razones de simplicidad diremos que este índice (expresado en tanto por uno, como sus componentes) es el resultado de minorar la media móvil de once términos de la tasa de variación de los ingresos del sistema $\left(\breve{g}_{I, t+1}\right)$ con la de gastos del mismo en pensiones contributivas $\left(\breve{g}_{p, t+1}\right)$-excluidos en uno y otro caso los no relevantes a efectos de pensiones $-\mathrm{y}$ con el «efecto sustitución» $\left(\breve{g}_{s, t+1}\right)$ - tal como se definió en Espina, 2017b-, agregando a todo ello la proporción que representa el desequilibrio entre ingresos y gastos respecto al gasto total del sistema (también en media móvil de once términos), aunque computando en este caso solo una fracción: entre la cuarta y la tercera parte, expresada por el símbolo a (revisable quinquenalmente).

Lo primero que puede decirse de este indicador es que, tal como está definido en la ley, resulta de imposible aplicación porque incurre en razonamiento circular, ya que para calcular el segundo miembro habría que conocer previamente el primero (Roch et al., 2015). Además, la fórmula no garantiza la convergencia de ingresos y gastos ni en el corto ni en el largo plazo. A mayor abundamiento, la solución dada por la reforma al objetivo de una aplicación automática, sin necesidad de intervención del Gobierno, tampoco se da, ya que en buena medida el resultado depende de las proyecciones realizadas por el propio Gobierno para los últimos seis años de las medias móviles. $D$ 


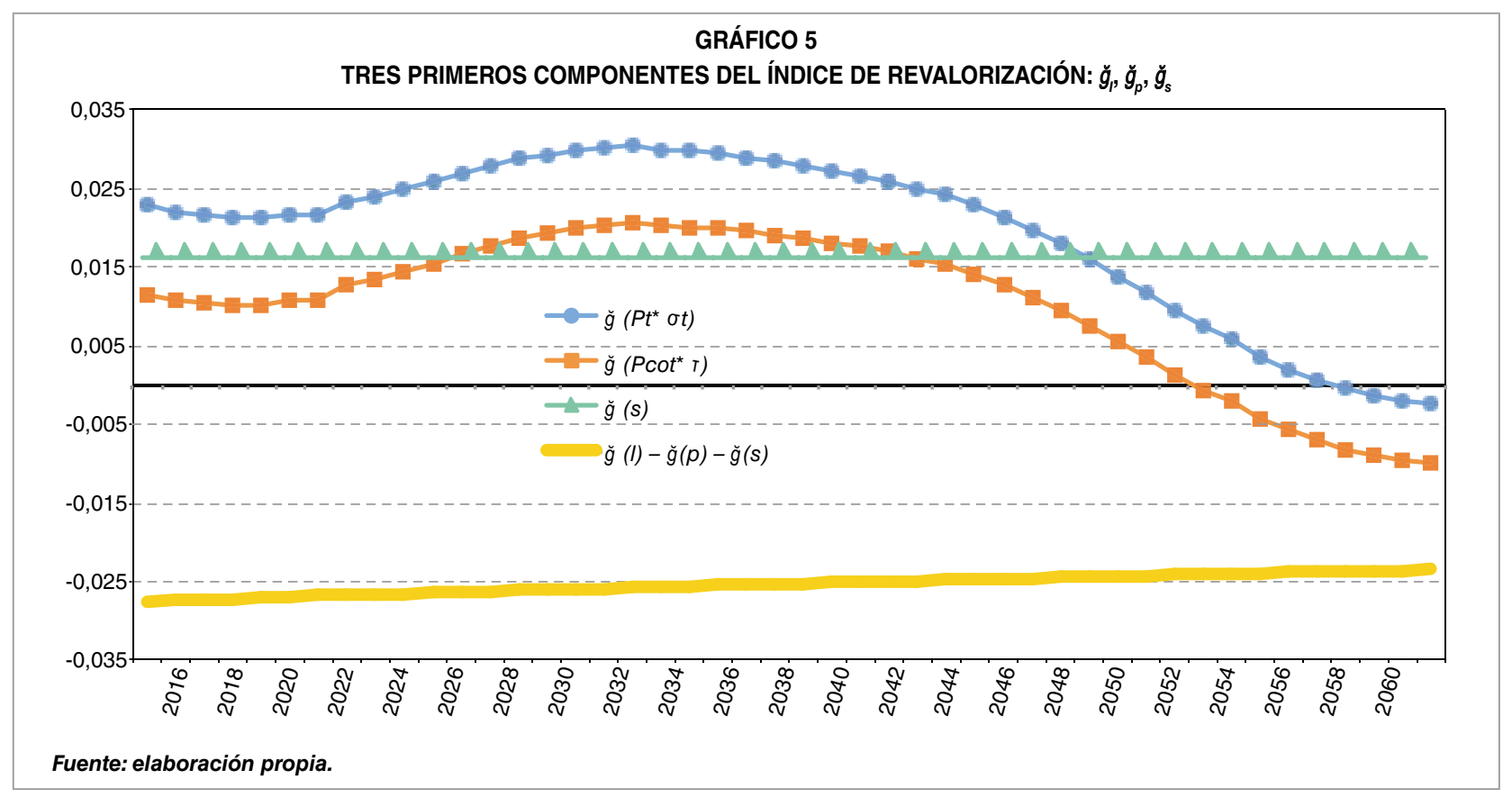

Finalmente, los límites superior (IPC+0,5 por $100)$ e inferior $(0,25$ por 100) para el índice de revalorización resultan incompatibles si el IPC es inferior a -0,25 por 100 .

Bien es verdad que, aunque no se dieran esas incongruencias, los órdenes de magnitud en que previsiblemente se moverán en el futuro los componentes de índice hacen inútil cualquier esfuerzo de cálculo, ya que en cualquier caso casi siempre resultará aplicable el límite de revalorización mínimo establecido por la propia ley, situado en el 0,25 por 100, como ha venido sucediendo desde su entrada en vigor ${ }^{23}$.

Una simple exploración tentativa de los escenarios más verosímiles para los componentes del índice de revalorización, empleando los mismos datos en que se basan nuestras proyecciones, indican que -en ausencia de una reforma en profundidad-, éste podría

23 Véanse las opiniones emitidas por la AIReF sobre las revalorizaciones de pensiones de 2015 y 2016, y especialmente la primera, con sus anexos de fórmulas, estimaciones y modelización de cuotas. También, Moral-Arce et al. (2018). evolucionar de forma explosiva. Veamos: tomaremos como proxy de la variable ingresos previsibles en el futuro el producto de la población cotizante $\left(E_{t}\right)$ sintetizada en el Cuadro $7 \mathrm{y}$ el tipo de cotización $(T)$ del Cuadro 6 (o sea: $E_{t}^{\star} T$ ) y de la variable gastos en pensiones el producto de la población de pensionistas y la ratio de reposición de los mismos cuadros (o sea: $P_{t}^{*} \sigma$ ), aumentado en un 26,38 por 100 para incluir pensiones de viudedad y familiares ${ }^{24}$. En Espina (2017b) puede observarse que desde 1986 hasta 2016 el promedio del efecto sustitución ha sido 0,16 y que, tras el descenso observado a partir de la reforma de 1985 (que elevó paulatinamente el período de cómputo), desde comienzos del nuevo milenio este efecto se ha estabilizado en torno a aquella cifra, por lo que en una proyección estimativa puede considerarse constante.

A partir de estas series podemos realizar los cálculos de las medias móviles de 11 términos (centradas en el sexto) para el período $\square$

24 Proporción que representa el gasto total en pensiones de viudedad, orfandad y familiares respecto al gasto en pensiones de jubilación el 1 de abril de 2017, que se mantiene considerablemente estable. 


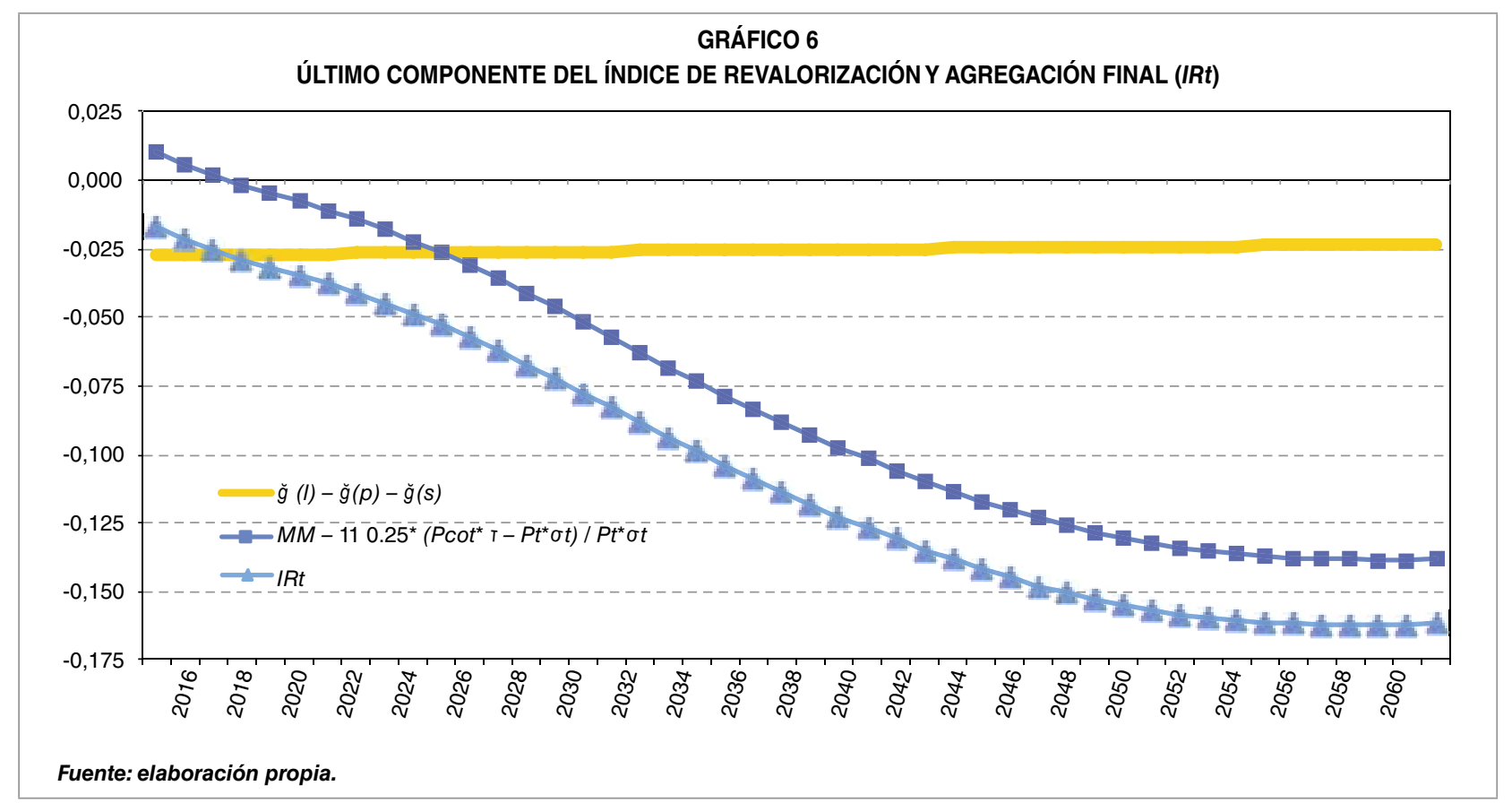

2016-2061 de los tres primeros términos del índice de revalorización (IR) previsto en la reforma de 2013. Estos tres componentes y su agregación se presentan en el Gráfico 5, en el que puede observarse que ya de la agregación de estos tres componentes derivaría un índice de revalorización inferior al $-0,25$ por 100 , al menos hasta el año 2041.

Pero lo que resultaría explosivo - en ausencia de correcciones- es el último componente del índice de revalorización, de acuerdo con los resultados presentados en el Gráfico $6^{25}$, según los cuales ya en 2016 arrancaría por debajo de 0,25 y llegaría a -0,138 en 2061, con lo que, agregado al resto de componentes, el IR se movería entre -0,017 en 2016 y -0,162 al final del período proyectado.

Esto significa que a la vista de nuestra proyección habría que aplicar el límite mínimo del IR $(0,0025)$ durante todo el período proyectado

25 En el que este componente se denomina MM - $110.25^{\star}\left(P \cot ^{\star}\right.$ $\left.T-P t^{\star} \sigma t\right) / P t^{\star} \sigma t$, aunque la cifra de gasto en pensiones de jubilación se encuentra aumentada también en un 26,38 por 100 . y, si así fuera, en el supuesto de que a largo plazo la inflación anual se sitúe en torno al 2 por 100 la pérdida de poder adquisitivo de las pensiones a lo largo de veintidós años ${ }^{26}$ sería del orden del 32 por 100.

Sin embargo, estos dos gráficos hacen un razonamiento estático y no toman en consideración la corrección del desequilibrio entre ingresos y gastos derivada de la merma del poder adquisitivo de las pensiones (que no afecta a los ingresos por cotizaciones). Como en todos nuestros cálculos se toma como unidad de medida el salario anual en cada momento (que evoluciona en relación con la inflación), para tener una visión dinámica debemos descontar del gasto en pensiones el efecto de aqueIla erosión (multiplicando por 0,9825, con una pérdida real de 0,0175), reestimando el nuevo IR y aplicándolo cuando resulta ser superior a 0,0025 , cosa que bajo aquellos supuestos solo sucedería entre 2021 y 2023.

26 El promedio de la esperanza media de vida del grupo de edades entre 65 y 70 años a lo largo de la proyección es de 21,8 años. 


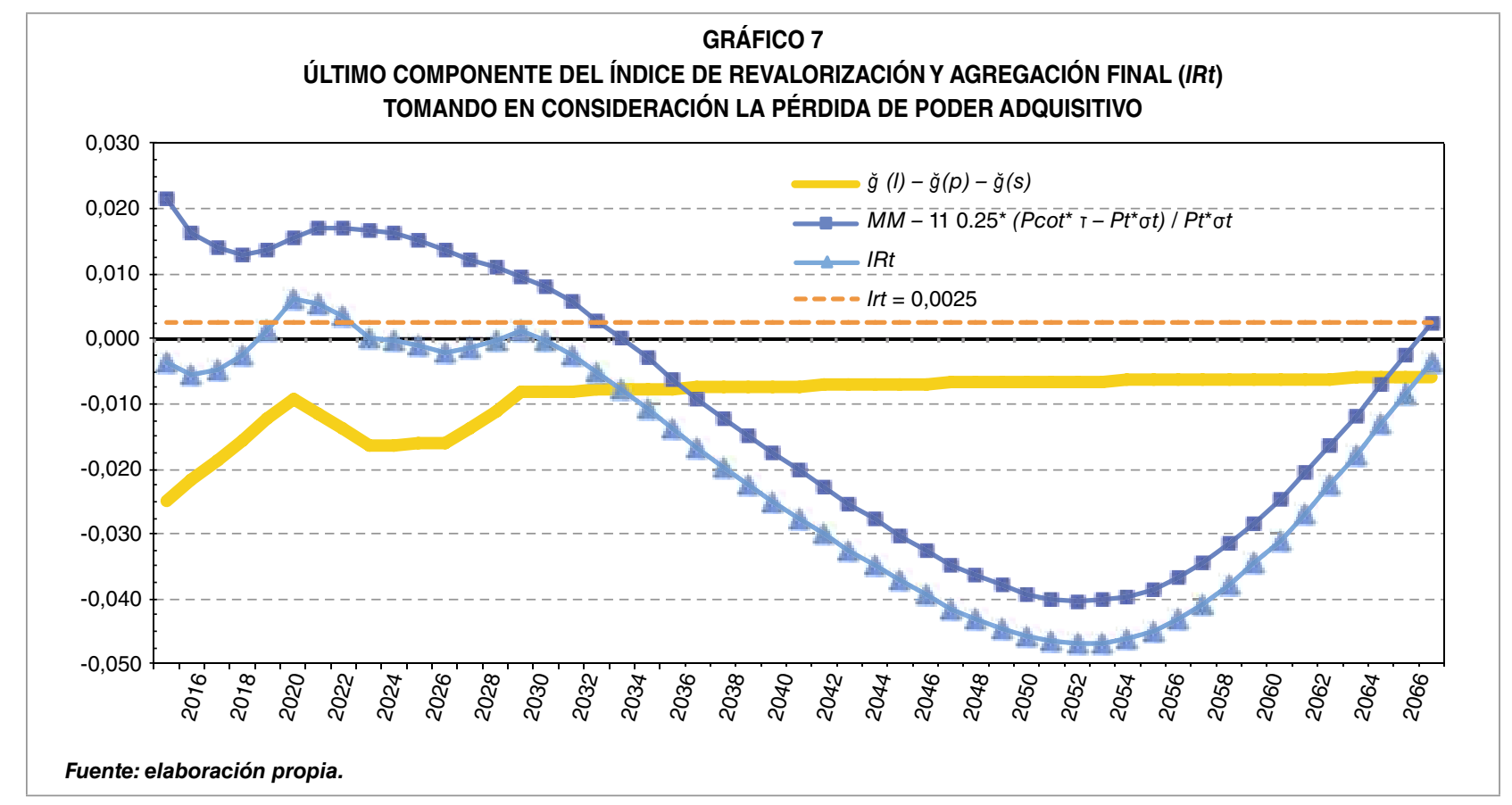

Antes de hacerlo, sin embargo, es preciso paliar la inconsistencia de este indicador, ya que el argumento circular estudiado por Roch et al. (2015) impide realizar tales cálculos iterativos. Nuestra propuesta consiste en redefinir todos los componentes del IR como la media móvil de seis términos, adelantada hasta el año en curso (o sea, para 2016 se toma la media del período 2011-2016). Una vez reestimada la serie año a año, se mantiene el corrector 0,9825 hasta 2021, año en que por primera vez el IR supera el umbral mínimo, situándose en 0,0062, que, al aplicarse en la revalorización del año subsiguiente, supone un índice de corrección del coste real de las pensiones de 0,9958 . Lo mismo sucede en 2022 (con un IR de 0,0053 y un corrector de 0,9967 para 2023) y en 2023 (con IR de 0,0033 y un corrector de 0,9987 para 2024). A lo largo del resto del período proyectado el IR se mantiene por debajo del límite de 0,0025, por lo que es este el IR aplicado (con pérdida real anual de 0,0175), como se observa en el Gráfico 7.
En el Gráfico 8 se presenta el resultado de este ejercicio tomando magnitudes equivalentes de ingresos por cotizaciones y gasto en pensiones (corregido en este caso por la erosión de su poder adquisitivo). Puede observarse que el equilibrio se pierde en 2032, alcanza un máximo equivalente a una quinta parte de los ingresos en 2050 y vuelve a recuperarse en 2063. Para ello, la aplicación del índice de revalorización habría producido una erosión creciente del poder adquisitivo de la pensión a lo largo del período completo de esperanza de vida, que va desde el 27 por 100 para quienes se jubilen en 2016 hasta el 33 por 100 para quienes lo hagan a partir de $2036^{27}$. O, lo que es lo mismo, en promedio, a lo largo del período de percepción de la pensión, los primeros perderían casi un 14 por 100 de poder adquisitivo y los últimos casi un 17 por 100 (todo ello en el supuesto de que la inflación media se situase en 2 por 100). Esto $\triangleright$

27 El promedio de la esperanza de vida entre 65 y 70 años de los primeros es 20 años; el de los segundos, 23 (cifras redondeadas). 


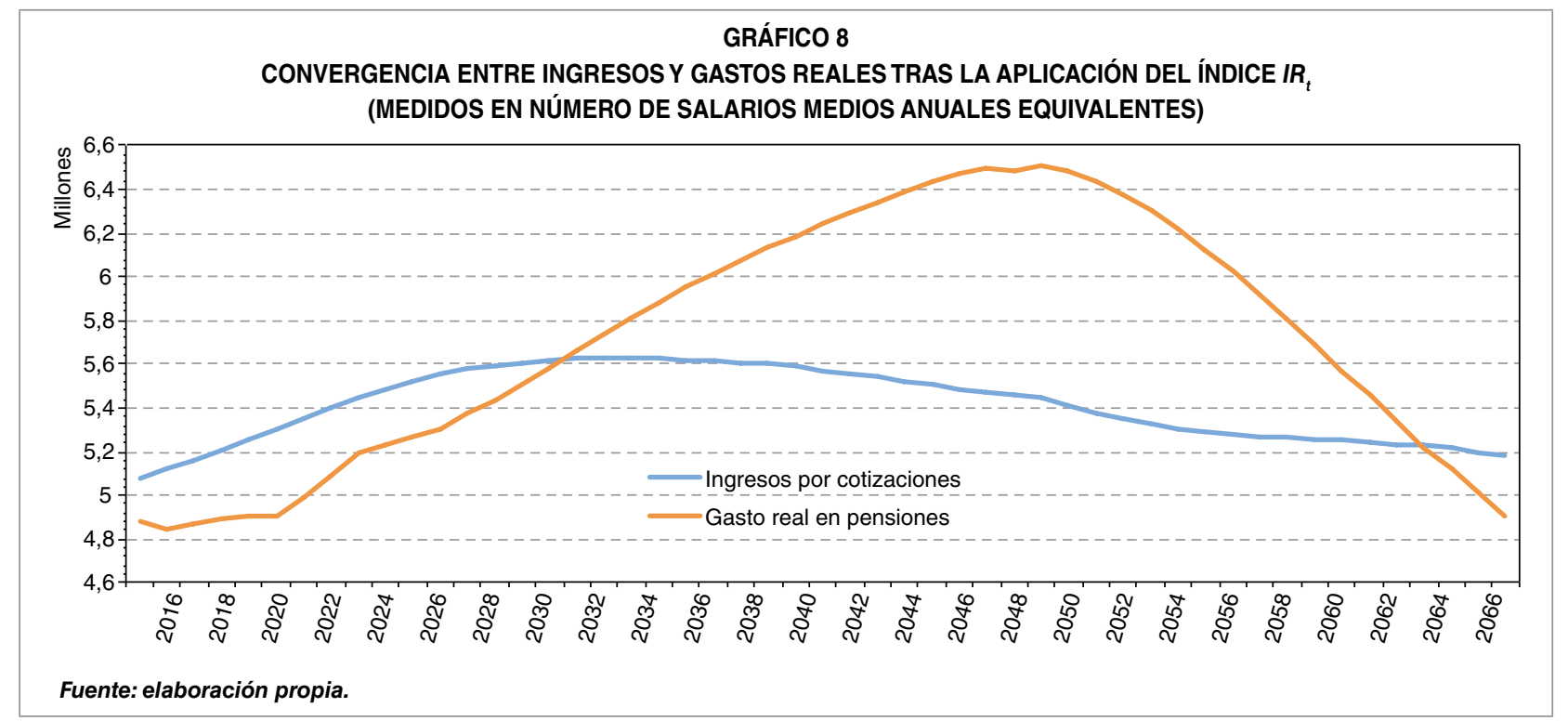

es, la corrección producida por el IR de la Ley 23/2013 terminaría por corregir el desfase entre ingresos y gastos que observábamos en el Cuadro 7, aunque no evitaría que el sistema incurriera en déficit durante el período 2032-2063 ni serviría para reabsorber los déficits acumulados durante ese período ${ }^{28}$, fruto del desfase entre las poblaciones de cotizantes y pensionistas, que rompen el principio de equidad intergeneracional ${ }^{29}$. Esto es, el mecanismo de revalorización terminaría por corregir el problema de equidad intergeneracional. Ahora bien, ¿es este el modo más adecuado de hacerlo?

\section{Una fórmula alternativa a la de 2013 para alcanzar la equidad intergeneracional y la sostenibilidad del sistema}

En el epígrafe anterior se observó que el mecanismo de corrección derivado de la Ley

28 Como ya anticipaban Roch et al. (2015).

29 Obsérvese que la erosión acumulada de poder adquisitivo en 2063 equivale casi exactamente al promedio de la reducción de la ratio $E_{t}{ }_{t} / P_{t}{ }_{t}$ entre 2060 y 2066 del Cuadro 7.
23/2013 es insuficiente y no es transparente en lo que se refiere a las expectativas respecto a la ratio de reposición inicial y al mantenimiento del poder adquisitivo de las pensiones durante el período de percepción, en un momento de su ciclo vital en que ya no resulta subsanable la eventual insuficiencia de ingresos. Todo ello aun en el caso hipotético de proceder a algunas correcciones: eliminar la incoherencia del «factor de sostenibilidad", sustituyéndolo por una absorción del aumento de la esperanza de vida mediante la prolongación de la edad de jubilación ordinaria; subsanar el problema de circularidad en el cálculo del índice de revalorización sustituyendo las medias móviles de once términos por otras de seis términos (prescindiendo de proyecciones discrecionales) y haciendo abstracción de la incertidumbre acerca del grado de corrección del valor real de la pensión, ya que el índice de revalorización no está referido al nivel de la inflación ${ }^{30}$.

30 Además de la eventual inconsistencia entre los límites máximo y mínimo, en el caso de que la inflación anual se situara por debajo de $-0,0025$. 
La forma alternativa de abordar los problemas de sostenibilidad del sistema de pensiones y de la ausencia de equidad intergeneracional consiste en acometer directamente la corrección de la ratio de reposición actual $(\sigma)$, claramente inconsistente con los cálculos actuariales que rigen todo sistema contributivo y con la capacidad financiera del sistema, a la vista de la evolución previsible del número de cotizantes. Tal corrección debe cumplir una serie de requisitos para resultar políticamente factible y socialmente equitativa. En primer lugar, debe realizarse gradualmente, ya que una reforma drástica e inmediata traicionaría gravemente las expectativas de mantenimiento de un poder adquisitivo aceptable en la vejez, sin permitir a la población afectada anticipar acontecimientos para tomar decisiones previsoras. En segundo lugar, la reforma debe establecer parámetros ciertos y previsibles, de modo que sus efectos puedan anticiparse y permitan actuar en consecuencia. En tercer lugar, debe afectar a toda la población, distribuyendo equitativamente sus efectos, lo que implica actuar tanto sobre la ratio de reposición inicial aplicable a las nuevas altas $\left(\sigma^{\star}\right)$ como sobre la que se va alcanzando en términos reales como consecuencia de los índices de revalorización aplicados anualmente $\left(\sigma_{t}\right)$. Además, al realizar una corrección gradualista, la $\sigma^{*}$ aplicada a la población ya jubilada antes de la reforma será superior a la de después de la reforma (y esta última resultará decreciente en el tiempo), por lo que una distribución equitativa implica que la corrección producida por los índices de revalorización sobre $\sigma_{t}$ sea más intensa al comienzo y vaya disminuyendo a medida que lo hace $\sigma^{*}$ y aumenta también la proporción de población ya jubilada a la que se le ha aplicado una ratio de reposición inicial descendente. Considerando en primer lugar el conjunto de pensiones del sistema, todos estos criterios se cumplen con una reforma apoyada sobre dos medidas:

A. Controlar la progresión de la ratio de reposición media de la pensión de jubilación del sistema (respecto al coste salarial anual) para que, partiendo del 60,2 por 100 actual $^{31}$, no supere el 72 por 100 al término del período. Suponiendo que los cambios en la ratio de reposición legal se transmiten íntegramente a la ratio de reposición de las nuevas altas en jubilación, dada la buena correlación existente entre estas últimas y las ratios medias del sistema (Gráfico 9), tal cosa se conseguiría reduciendo la tasa de reposición legal respecto a la base reguladora de la pensión desde el 100 por 100 actual hasta el 75 por 100 en 2052 -a razón de una reducción de medio punto porcentual al año desde 2018 hasta 2037 y de un punto anual hasta 2052-, manteniéndola en ese nivel hasta el final del período proyectado ${ }^{32}$.

B. Aplicar una reducción del poder adquisitivo de las pensiones ya devengadas utilizando un índice de revalorización por debajo del nivel de inflación anual, de intensidad decreciente en el tiempo. $\triangleright$

31 Cifra resultante para 2016 de la tendencia lineal observada durante el período 1981-2016: Espina (2017b, Cuadro A-3 y Gráfico 17). En ausencia de reforma, la proyección indica que superaría el 85 por 100 en 2053 (Cuadro 4) y el 90 por 100 a partir de 2065.

32 Denominando $\sigma_{t t}$ a la ratio legal aplicable, $\sigma_{\text {at }}$ a la ratio media anual de las nuevas altas y $\sigma_{s t}$ a la ratio media anual del sistema, se construye primero la serie de $\sigma_{t t}$ partiendo de 1 en 2017 hasta 0,9 en 2037 y 0,75 en 2052 (manteniendo esta última constante hasta 2066); a continuación se estima la serie de $\sigma_{\text {st }}$ proyectada en ausencia de reforma mediante extrapolación de la tendencia lineal observada entre 1976 y 2016 (Espina 2017 b, Cuadro A-3; Gráfico 16), que figuraba en el Cuadro 5. Esta serie se transforma en una de $\sigma_{a t}$ pre-reforma, despejando la $x$ de la ecuación del Gráfico 9: $\sigma_{a t}=\left(\sigma_{s t}-0,065\right) / 0,6796$, y se le aplica la reforma multiplicándola por la nueva $\sigma_{1 t}$. Finalmente, la serie $\sigma_{a t}$ reformada se convierte en $\sigma_{s t}$ reformada con la expresión $\sigma_{s t}=0,065+0,6796 \sigma_{a t}$. La serie del gasto en pensiones es el producto de esta ratio por la población de pensionistas $\left(P_{t}:\right.$ Cuadro 7), elevada en un 26,38 por 100 por las pensiones familiares. 
Suponiendo una inflación del 2 por 100, la pérdida de poder adquisitivo con el índice de revalorización de la Ley 23/2013 sería del 1,75 por 100 anual. La nueva reforma aplicaría esa misma reducción solo el primer año, disminuyéndola a razón de 0,0306 puntos porcentuales al año (de manera que la pérdida sería de 1,72 por 100 en 2018 , de 1,69 por 100 en $2019 \ldots$, y de 0,25 por 100 en 2066). Esta merma del poder adquisitivo se mantendría cualquiera que fuere la inflación del año en curso, sin umbrales de ningún tipo, excepto en el caso de que en las $\triangleright$

\section{GRÁFICO 9}

REGRESIÓN DE LAS RATIOS DE REPOSICIÓN: NUEVAS ALTAS $(x)$ Y MEDIA DEL SISTEMA (y). DATOS REALES (1981-2016) Y PROYECCIÓN (2017-2066), CON REDUCCIÓN PAULATINA DE LA RATIO LEGAL INICIAL DESDE EL $100 \%$ HASTA EL 75\%

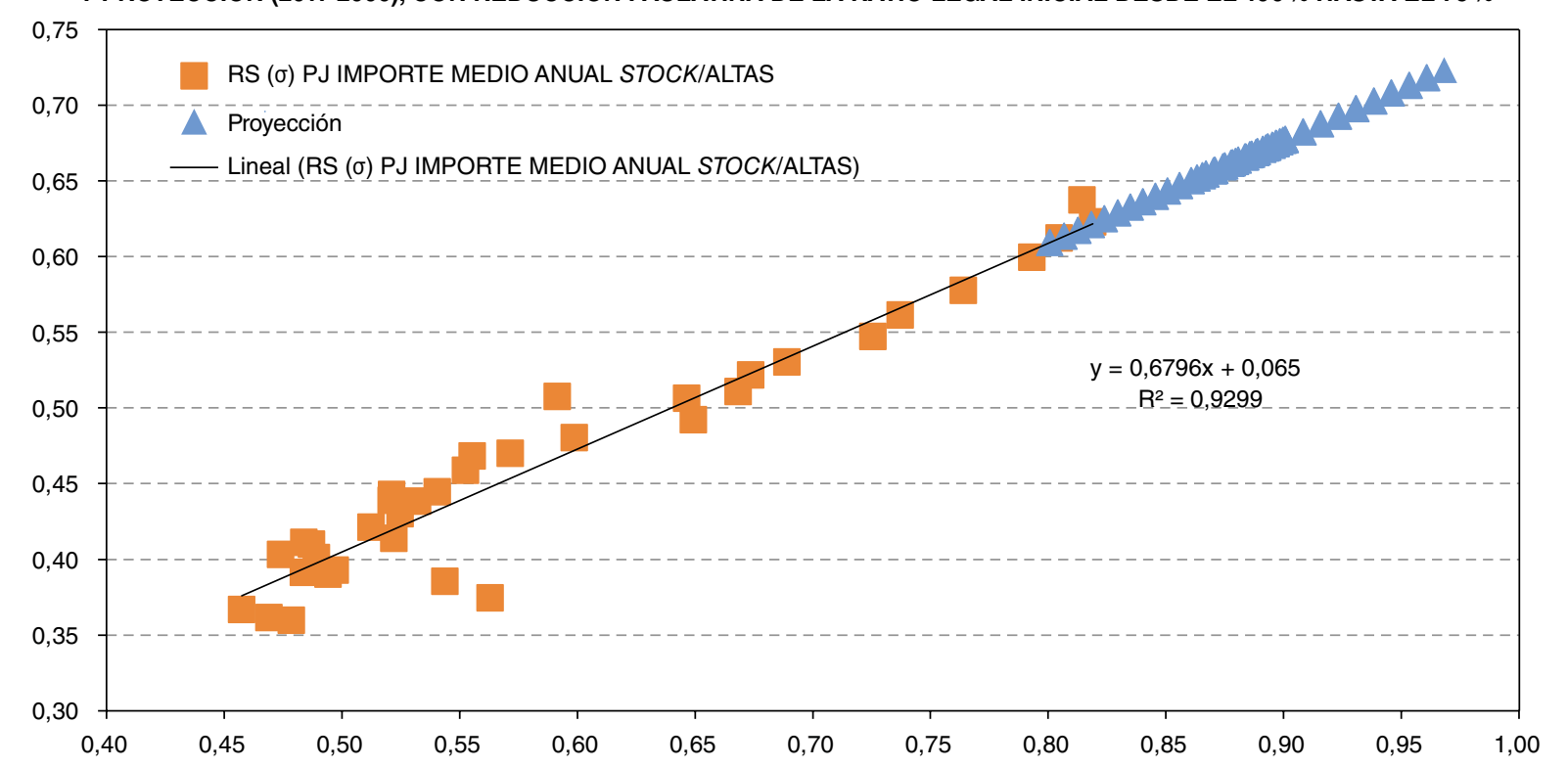

Fuente: elaboración propia.

CUADRO 8

INGRESOS/GASTOS; RATIO DE REPOSICIÓNY REVALORIZACIÓN PRE Y POST-REFORMA

\begin{tabular}{|llccccccc|}
\hline & & $\mathbf{2 0 1 7}$ & $\mathbf{2 0 2 0}$ & $\mathbf{2 0 3 0}$ & $\mathbf{2 0 4 0}$ & $\mathbf{2 0 5 0}$ & $\mathbf{2 0 6 0}$ & $\mathbf{2 0 6 6}$ \\
\hline$(1) P \cot ^{*} T$ & $(T=0,2554)$ & 5,117 & 5,252 & 5,610 & 5,587 & 5,411 & 5,250 & 5,186 \\
$\sigma_{s t}$ & Pre-reforma & 0,609 & 0,630 & 0,698 & 0,766 & 0,834 & 0,902 & 0,942 \\
$\sigma_{a t}$ & Pre-reforma & 0,801 & 0,831 & 0,931 & 1,031 & 1,131 & 1,231 & 1,291 \\
$\sigma_{l t}$ & Post-reforma $\sigma$ & 1,000 & 0,985 & 0,935 & 0,870 & 0,770 & 0,750 & 0,750 \\
$\sigma_{a t}$ & Post-reforma $\sigma$ & 0,801 & 0,818 & 0,870 & 0,897 & 0,871 & 0,923 & 0,968 \\
$\sigma_{s t}$ & Post-reforma $\sigma$ & 0,609 & 0,621 & 0,656 & 0,675 & 0,657 & 0,692 & 0,723 \\
$P t^{*} \sigma_{s t}{ }^{*} 1,2638$ & Pre-reforma $\sigma$ & 5,014 & 5,353 & 6,868 & 9,202 & 11,498 & 11,804 & 11,549 \\
$P t^{*} \sigma_{s t}{ }^{*} 1,2638$ & Post-reforma $\sigma$ & 5,014 & 5,281 & 6,463 & 8,107 & 9,060 & 9,066 & 8,861 \\
$I R$ & Post-reforma IR & $\mathrm{pt}-1,75 \%$ & $\mathrm{pt}-1,66 \%$ & $\mathrm{pt}-1,35 \%$ & $\mathrm{pt}-1,05 \%$ & $\mathrm{pt}-0,74 \%$ & $\mathrm{pt}-0,43 \%$ & $\mathrm{pt}-0,25 \%$ \\
$(10) P t^{*} \sigma_{\text {st }}{ }^{*} 1,2638$ & Post-reforma $\sigma \& I R$ & 4,859 & 4,863 & 5,123 & 5,704 & 5,837 & 5,515 & 5,286 \\
$(1)-(10)$ & & 0,257 & 0,389 & 0,488 & $-0,117$ & $-0,426$ & $-0,265$ & $-0,100$ \\
$\sigma_{s t}($ con familiares) & Post-reforma $\sigma \& I R$ & 0,590 & 0,572 & 0,520 & 0,475 & 0,423 & 0,421 & 0,431 \\
\hline Fuente: elaboración propia. & & & & & & & \\
\hline
\end{tabular}


revisiones periódicas quinquenales la evolución observada contradijera sistemáticamente las tendencias resultantes de esta proyección.

El Cuadro 8 presenta los resultados de la simulación de esta doble reforma. En él, las ratios se computan en tanto por uno; las magnitudes de ingresos y gastos (y superávit/déficit), en millones de unidades de salario medio anual del año en curso (con lo que se evita simular escenarios de inflación), y el índice de revalorización (IR) se expresa como diferencia respecto de la inflación anual $\left(p_{t}\right.$, en porcentaje). En el Gráfico 10 se representa la evolución de ingresos y gastos, junto al fondo acumulado de superávit (para alimentar el fondo de reserva) durante el período 2018-2037, que sirve para enjugar el déficit esperado entre 2038 y 2066, momento en que ya solo equivale al 1,9 por 100 del gasto anual, mientras el fondo de reserva no llega a superar el monto de dos anualidades de gasto en pensiones (en cambio, de fijar una senda sin pérdida de poder adquisitivo desde 2066 , el déficit del $2 .^{\circ}$ período casi duplicaría al fondo del 1.ํ).
La reforma propuesta cumple todos los requisitos enunciados al comienzo de este epígrafe: gradualismo, certidumbre y previsibilidad de los parámetros, equidad en la distribución de la carga entre los ya jubilados y los futuros pensionistas, y modulación en la intensidad de la pérdida de poder adquisitivo derivada del índice de revalorización, a medida que estos últimos van experimentando la acumulación en la reducción de la ratio inicial. Cumple también grosso modo el requisito de equilibrio intergeneracional derivado de la ecuación $\left[E_{t} / P_{t}=\right.$ $\sigma^{*} \cdot\left(1 / \mathrm{T}_{t}\right)$ ], ya que el descenso en la ratio $E{ }_{t} / P$ " que se observaba en el Cuadro 7 (del 31,3 por 100), se ve bastante aproximado por el descenso que registra la ratio de sustitución $\left[\sigma_{s t}\right]$ entre 2016 y 2066 , que se sitúa en 27,4 por 100, aunque en el Cuadro 8 sea algo menor $(27$ por 100$)$ porque esta serie comienza en 2017.

Sin embargo, la consecución del objetivo de equidad intergeneracional no permite mantener el de equidad actuarial intrageneracional, ya que, incluso en el escenario con una tasa de retorno del 1 por 100 , el fondo acumulado para la pensión comienza a $D$

GRÁFICO 10

RESULTADOS DE LA REFORMA: INGRESOSY GASTOS; FONDO O DÉFICIT ACUMULADO

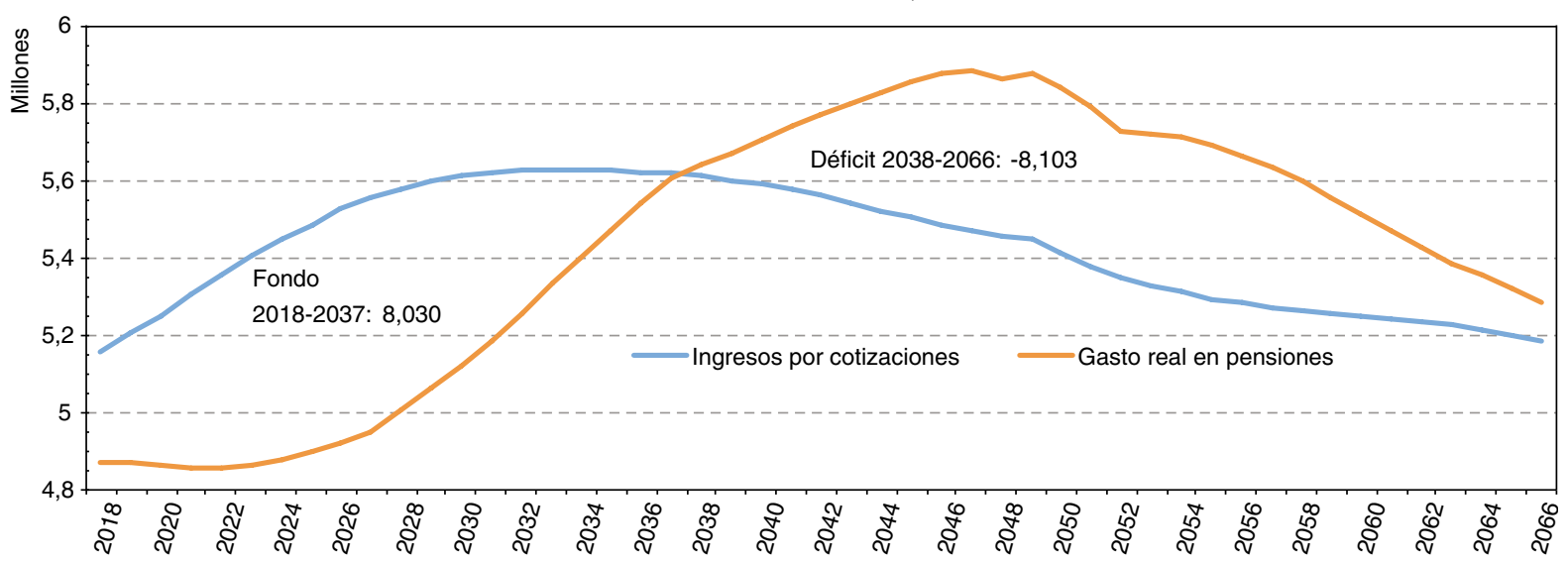

Fuente: elaboración propia. 
CUADRO 9

INGRESOS/GASTOS; RATIO DE REPOSICIÓNY REVALORIZACIÓN PRE Y POST-REFORMA

DE LA PENSIÓN DE JUBILACIÓN EN EL RÉGIMEN GENERAL

\begin{tabular}{|c|c|c|c|c|c|c|c|c|}
\hline & & 2017 & 2020 & 2030 & 2040 & 2050 & 2060 & 2066 \\
\hline (1) $\operatorname{Pcot}^{\star} T$ & $T=0,1999$ & 4,004 & 4,110 & 4,391 & 4,373 & 4,235 & 4,109 & 4,058 \\
\hline$\sigma_{s t}$ & Pre-reforma & 0,68 & 0,70 & 0,78 & 0,85 & 0,92 & 0,99 & 1,04 \\
\hline$\sigma_{a t}$ & Pre-reforma & 0,87 & 0,91 & 1,04 & 1,17 & 1,31 & 1,44 & 1,52 \\
\hline$\sigma_{l t}$ & Post-reforma $\sigma$ & 1,00 & 0,99 & 0,94 & 0,87 & 0,77 & 0,70 & 0,70 \\
\hline$\sigma_{a t}$ & Post-reforma $\sigma$ & 0,87 & 0,89 & 0,97 & 1,02 & 1,01 & 1,01 & 1,06 \\
\hline$\sigma_{s t}$ & Post-reforma $\sigma$ & 0,68 & 0,69 & 0,74 & 0,76 & 0,76 & 0,76 & 0,79 \\
\hline$P t^{\star} \sigma_{s t}$ & Pre-reforma $\sigma$ & 4,429 & 4,723 & 6,038 & 8,065 & 10,053 & 10,298 & 10,064 \\
\hline$P t^{\star} \sigma_{s t}$ & Post-reforma $\sigma$ & 4,429 & 4,673 & 5,750 & 7,273 & 8,261 & 7,853 & 7,648 \\
\hline IR & Post-reforma IR & $p_{t} \%-1,75 \%$ & $\mathrm{p}_{\mathrm{t}} \%-1,66 \%$ & $p_{t} \%-1,35 \%$ & $p_{t} \%-1,05 \%$ & $p_{t} \%-0,74 \%$ & $\mathrm{p}_{\mathrm{t}} \%-0,43 \%$ & $p_{t} \%-0,25 \%$ \\
\hline (10) $P t^{\star} \sigma_{s t}$ & Post-reforma $\sigma \& I R$ & 4,293 & 4,304 & 4,558 & 5,117 & 5,322 & 4,777 & 4,562 \\
\hline (1)-(10) & & $-0,289$ & $-0,194$ & $-0,167$ & $-0,745$ & $-1,088$ & $-0,669$ & $-0,504$ \\
\hline$\sigma_{s t}$ & Post-reforma $\sigma \& I R$ & 0,66 & 0,64 & 0,59 & 0,54 & 0,49 & 0,46 & 0,47 \\
\hline
\end{tabular}

superar al capital-coste de las prestaciones en un 7 por 100 del primero ya en 2024, aumentando casi en diez puntos porcentuales cada diez años (situándose en 32 por 100 a partir de 2050, evolución simétrica a la del Cuadro 5, aunque añadiendo aquí orfandad y otros familiares).

\section{Sostenibilidad de la pensión de jubilación en el Régimen General tras la reforma}

Bien es verdad que la fórmula de proyección que venimos empleando puede resultar engañosa al realizar la elevación del tipo de cotización imputable a la pensión de jubilación - para incluir el resto de las modalidades de pensión asociadas (excepto la invalidez previa a la edad legal de jubilación) - con la proporción actual del peso del gasto en estas pensiones sobre el total, haciendo lo mismo con este último y calculando después la ratio de reposición pensión/salario a partir de las cifras resultantes. En puridad, estas cifras introducen un sesgo que distorsiona tanto el significado de la ratio como las conclusiones acerca de la sostenibilidad. Para razonar de manera más ajustada conviene realizar de nuevo toda la proyección pero limitándonos a la pensión de jubilación. Además, dado el carácter asintótico que tiene el Régimen General en todo nuestro sistema de pensiones, los cálculos de la ratio de reposición (respecto al coste salarial ordinario medio) deben circunscribirse a este último, que está llamado a absorber a todos los demás, ya directamente -como se hizo con el de clases pasivas del Estado-, ya aplicando los parámetros a los regímenes especiales subsistentes ( $\mathrm{y}$ al de clases pasivas a extinguir), con su misma lógica.

Además, dados los desequilibrios que se observan en una primera proyección hasta el final del período proyectado, resulta imprescindible prorrogar la reducción de la ratio de reposición legal hasta alcanzar el 70 por 100 en 2057, manteniéndola en ese nivel hasta 2066. Los resultados de este ejercicio se muestran en el Cuadro 9 y la comparación de las ratios $\triangleright$ 


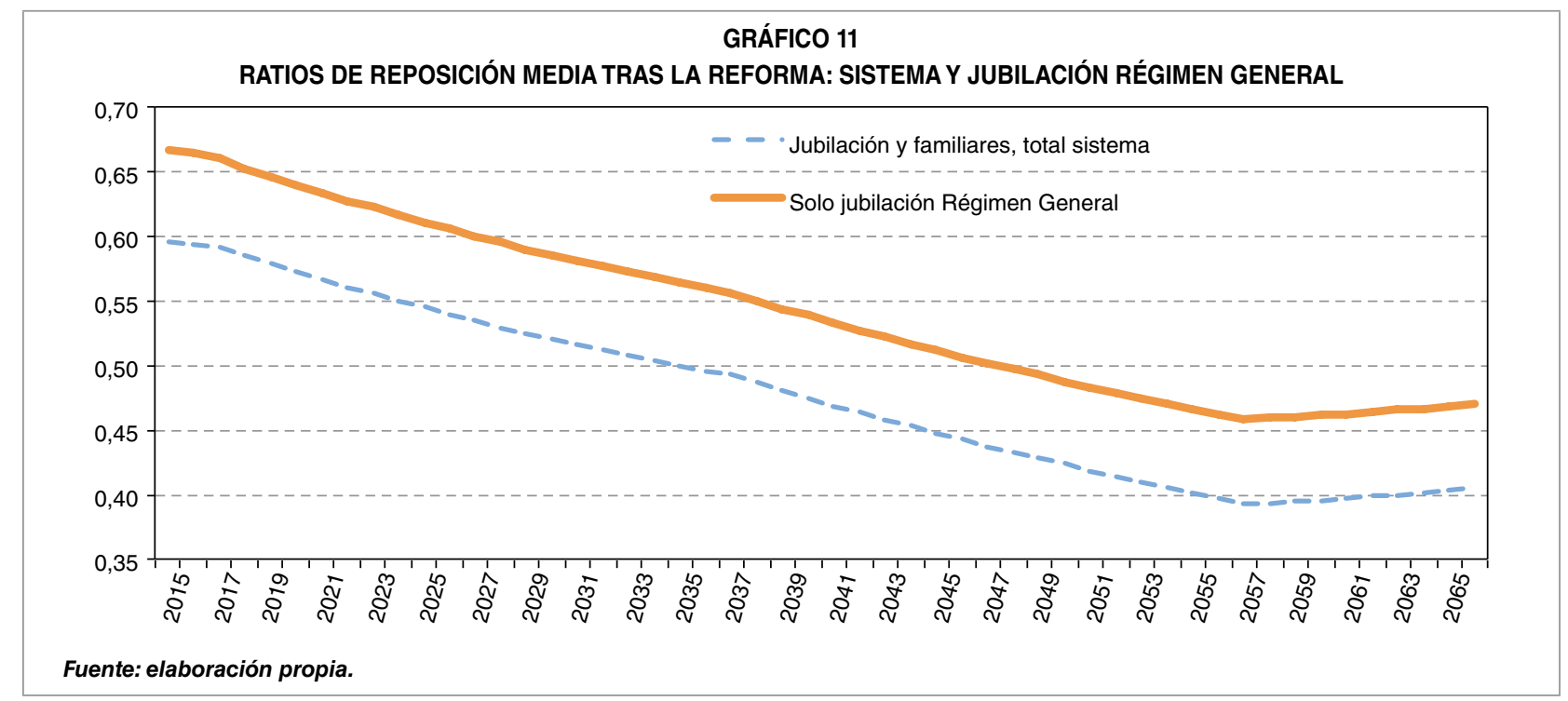

de reposición resultantes con las del ejercicio anterior respecto al total del sistema con pensiones de jubilación y familiares se dibujan en el Gráfico $11^{33}$.

En el Gráfico 11 puede observarse el paralelismo entre las tendencias de uno y otro ejercicio, así como la prolongación en cinco años del descenso de la ratio legal de reposición en la proyección de la jubilación en el Régimen General. En síntesis, la ratio media pasa del 59 por 100 al 43 por 100 en la simulación de la reforma hecha con el total del sistema y del 66 por 100 al 47 por 100 en el Régimen General (con descensos de 16 y 19 puntos porcentuales, o sea, del 26 por 100 y el 28 por 100 de la ratio inicial, respectivamente).

En segundo lugar, se observa que para la pensión de jubilación en el Régimen General el cómputo de equilibrio/desequilibrio tras la reforma arroja déficits de manera continuada. Tales déficits se elevan al 13,5 por 100 de los ingresos computables (ya se estimen unos y

\footnotetext{
33 En este caso la expresión del ajuste tendencial de la relación entre pensión inicial $\left(\sigma_{a t}=x\right)$ y pensión media $\left(\sigma_{s t}=y\right)$ es: $y=0,5466 x+0,2073$. Las series sobre las que se realiza el ajuste figuran también en Espina (2017 b, Cuadro A-3; la tendencia lineal de largo plazo de $\sigma_{s t}$ aparece en el Gráfico 16).
}

otros en promedio anual, ya computando el sumatorio de todo el período). Dado que el tipo de cotización imputable a esta pensión equivale al 19,99 por 100 de la base de cotización, subsanar tales déficits exigiría elevar el tipo de cotización en 2,7 puntos porcentuales, lo que no resulta practicable por las razones ya aducidas. La búsqueda de la sostenibilidad debe realizarse por otras vías.

Una de las primeras cuestiones a considerar es el diseño actual de la pensión de viudedad. A falta de un debate público acerca de la cuestión, no cabe entrar aquí en consideraciones acerca del origen de esta forma de protección —asociada históricamente a la segmentación de la participación en la actividad laboral derivada de la división del trabajo dentro de la familia en función del sexo de los cónyuges-; ni a la evolución experimentada por el trasfondo sociológico de la realidad que da pie a la misma; ni tampoco a la evolución de la doctrina del Tribunal Constitucional español, de claro signo expansivo, en la que se observa un abierto deslizamiento desde una consideración según la cual el hecho protegido era la situación de necesidad en que queda el cónyuge $D$ 
superviviente tras la muerte de su sustentador principal a otra en que de lo que se trata es de cubrir el riesgo de la disminución de ingresos causada por el fallecimiento de cualquiera de ellos cuando el otro es activo (Rabanal, 2017), lo que difiere considerablemente de la evolución que experimentan otros países europeos, en donde la evolución sociológica ha ido teniendo cabida en el diseño de esta pensión (Llorente-Moreno, 2017) ${ }^{34}$.

Lo que sí cabe es señalar la asimetría que se registra, desde el 15 de marzo de 2013 (tras la entrada en vigor del Decreto-Ley 5/2013), entre la compatibilidad prácticamente absoluta de la pensión de viudedad con la realización de cualquier trabajo remunerado ${ }^{35} \mathrm{y} / \mathrm{o}$ con la percepción de una pensión de jubilación causada por la persona que percibe aquella (acumulándose una y otra, con el límite de la pensión máxima), por un lado, y la incompatibilidad de la pensión plena de jubilación con la realización de una trabajo asalariado a tiempo completo y con la del trabajo por cuenta propia que produzca ingresos superiores al SMI. En estos casos la compatibilidad implica la reducción de la pensión de jubilación en un 50 por 100. Para romper la asimetría, ese mismo tratamiento debería tener la pensión de viudedad cuando se compatibiliza con un trabajo remunerado —con ingresos superiores al salario mínimoo con una pensión contributiva superior a la pensión mínima de jubilación. Como ya se dijo, las pensiones de viudedad que se compatibilizan con las de jubilación representan actualmente el 29,65 por 100 del total y su gasto equivale al 5,2 por 100 del gasto total en pensiones. Reduciendo su cuantía en un 50 por 100 el

\footnotetext{
34 Para una sinopsis de los sistemas de seguridad social en 34 países de Europa (epígrafe: Survivor Benefits) véase: https://www.ssa.gov/ policy/docs/progdesc/ssptw/2010-2011/europe/index.htm/\#fileList

35 Ley General de la Seguridad Social. RDL 8/2015, artículo 223.
}

ahorro de gasto equivaldría al 2,6 por 100 del mismo, lo que (de aplicarse este ahorro al elevar la imputación del tipo de cotización destinado a la pensión de jubilación) equivaldría a elevar el tipo de cotización para la pensión de jubilación en 0,73 puntos porcentuales (hasta 20,72 por 100), dejando todavía un descubierto equivalente a 1,9 puntos porcentuales de cotización.

La única forma lógica de enjugar esa insuficiencia aparente consiste en deducir del capítulo de gastos de nuestra proyección (que se basa en extrapolaciones a partir de las series de prestaciones percibidas, sin contemplar la forma de financiación con que han contado y con la que presumiblemente seguirán contando en el futuro) el complemento de mínimos de las pensiones, que -aunque figure agregada al resto de la pensión en las estadísticas correspondientes, y en nuestra proyeccióntiene en realidad carácter de prestación no contributiva, ya que propiamente esa es su función, tipificada en la metodología OCDE/UE como parte del primer pilar del sistema de pensiones, de acuerdo con el Diagrama 1, su devengo y cuantía no dependen de los derechos acumulados a través de la cotización (cuando se han cumplido los otros requisitos para adquirir el derecho). Durante el período para el que contamos con información (2005-2016), el gasto total en complemento de mínimos ha significado de media el 6,84 por 100 del gasto total en pensiones y desde 2013 el presupuesto del Estado ya viene asumiendo esa partida plenamente ${ }^{36}$. De este modo, el gasto en pensiones imputable al sistema contributivo en nuestra proyección debe corregirse con el factor correspondiente $(0,9316)$. Los resultados $\triangleright$

36 La liquidación de esta partida en 2016 supuso una transferencia del Estado de 7.195 millones de euros, y se incluye otra similar para 2017 (SESS, 2017, p. 57). Sobre esta cuestión véase López Cumbre (2014). 
CUADRO 10

INGRESOS/GASTOS DE LA PENSIÓN DE JUBILACIÓN EN EL RÉGIMEN GENERAL TRAS LA REFORMA DE LA PENSIÓN DE VIUDEDAD Y EL COMPLEMENTO DE MÍNIMOS

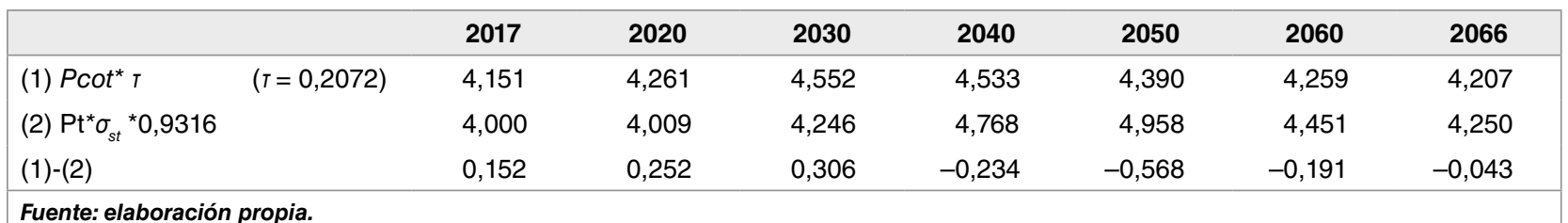

Fuente: elaboración propia.

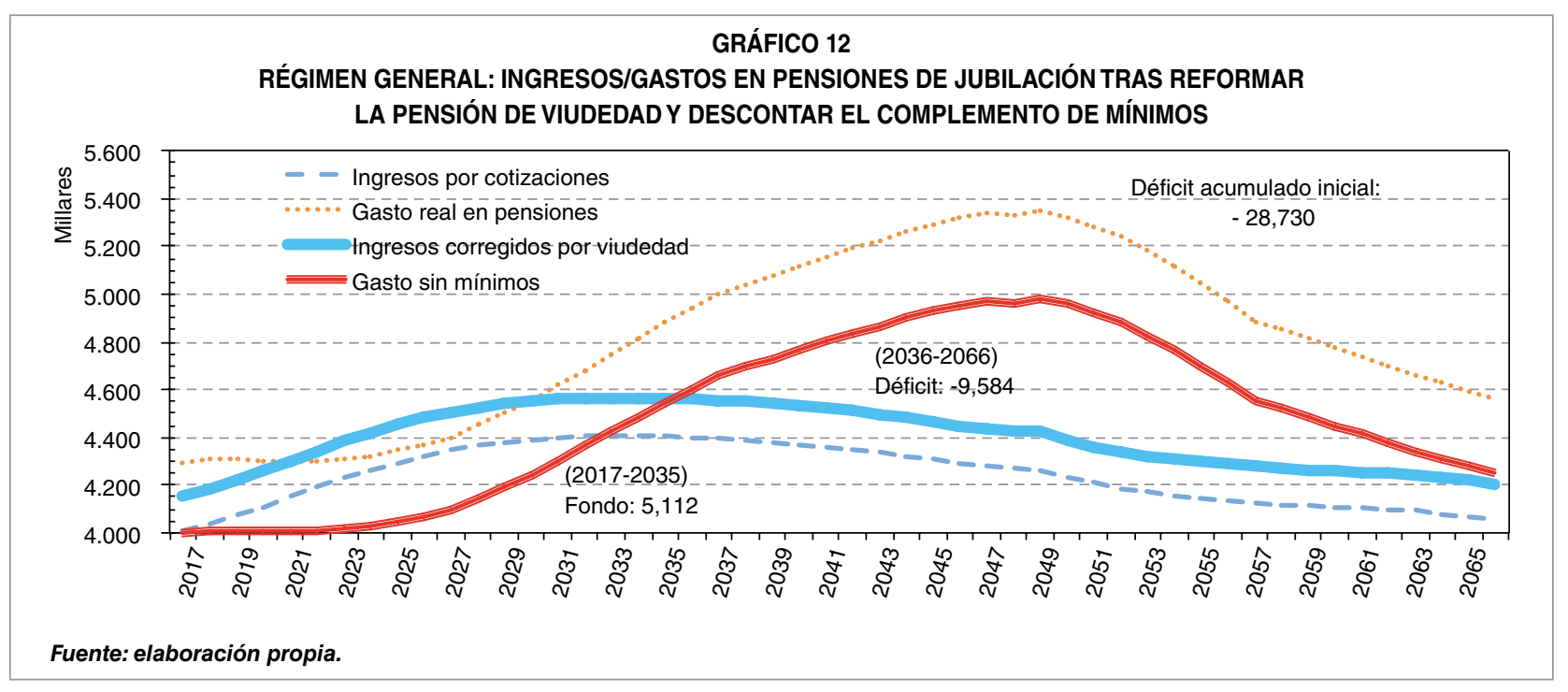

de ambas operaciones y el saldo se presentan en el Cuadro 10.

Puede observarse que, tras este conjunto de reformas e imputaciones corregidas, los ingresos por cotizaciones para jubilación en este régimen prácticamente se congelan (crecen al ritmo de 0,042 por 100 anual), mientras que los gastos imputables crecen a un modesto 0,105 por 100 anual. El saldo resultante presenta la forma de una $\mathrm{J}$ invertida e inclinada hacia adelante que entra en déficit en 2036, alcanza su punto máximo en 2050 (por un monto de 0,568 millones de unidades de salario medio anual de ese año), pero se corrige al final, hasta llegar a 2066 con un déficit equivalente a 43.000 unidades de salario/año (el doble del déficit medio acumulado a lo largo de todo el período, de 89.434 unidades anuales, equivalente al 2 por 100 del gasto total). Las magnitudes del déficit residual se encuentran por debajo del margen de error imputable a este tipo de proyecciones a tan largo plazo. En cualquier caso, podría neutralizarse con una elevación del tipo de cotización para la jubilación en el Régimen General de 0,4 puntos porcentuales —o de 0,2 puntos si solo consideramos el 50 por 100 por margen de error (lo que significaría elevar el tipo de cotización en el Régimen General del 28,3 por 100 al 28,5 por 100)-.

En este caso, una vez conseguido el objetivo de equidad intergeneracional, el objetivo de equidad actuarial intrageneracional resulta mucho menos dañado tras lo sucedido en el conjunto del sistema de pensiones, ya que, manteniendo prácticamente fijo el tipo de cotización efectivo (aunque se compute de $\triangleright$ 
CUADRO 11

EQUILIBRIO ACTUARIAL INTRAGENERACIONAL DEL SISTEMA DE PENSIONES DE JUBILACIÓN EN EL RÉGIMEN GENERAL TRAS LAS REFORMAS (INCLUYENDO MÍNIMOS)

\begin{tabular}{|c|c|c|c|c|c|}
\hline $\begin{array}{l}\text { Edad de jubilación } \\
n / \eta\end{array}$ & $\begin{array}{c}65,5 \\
37,4 / 20,6\end{array}$ & $\begin{array}{c}67,0 \\
38,9 / 20,7\end{array}$ & $\begin{array}{c}67,9 \\
39,8 / 21,2\end{array}$ & $\begin{array}{c}68,7 \\
40,6 / 21,6\end{array}$ & $\begin{array}{c}70,0 \\
41,9 / 22,4\end{array}$ \\
\hline$F P$ & $\tau=20,7 \%$ & $\tau=20,7 \%$ & $\tau=\mathbf{2 0}, \mathbf{7} \%$ & $T=20,7 \%$ & $T=20,7 \%$ \\
\hline$i=0,01$ & 9,3 & 9,8 & 10,1 & 10,3 & 10,7 \\
\hline$i=0,015$ & 10,3 & 10,8 & 11,2 & 11,5 & 12,0 \\
\hline$C P$ & $\sigma=65 \%$ & $\sigma=60 \%$ & $\sigma=55 \%$ & $\sigma=50 \%$ & $\sigma=47 \%$ \\
\hline$i=0,01$ & 12,2 & 11,2 & 10,5 & 9,7 & 9,4 \\
\hline$i=0,015$ & 11,6 & 10,6 & 9,9 & 9,2 & 8,9 \\
\hline \multicolumn{6}{|l|}{$F P-C P$} \\
\hline$i=0,01$ & $-2,8$ & $-1,4$ & $-0,4$ & 0,6 & 1,3 \\
\hline$i=0,015$ & $-1,3$ & 0,2 & 1,2 & 2,3 & 3,1 \\
\hline Proyección año & 2018 & 2027 & 2038 & 2047 & 2066 \\
\hline
\end{tabular}

distinta forma), en el escenario más pesimista el fondo acumulado para la pensión se mantiene en déficit hasta mediados de los años cuarenta, en que comienza a superar al capital-coste de las prestaciones, llegando a 2066 con un desfase positivo de tan solo 1,3 anualidades (un 12,5 por 100 del fondo). En cambio, con el escenario de crecimiento al 1,5 por 100 , el superávit aparece antes de 2030 y al final del período lo aportado supera a lo recibido en un 25,8 por 100 (Cuadro 11, que incluye los complementos a mínimos, al ser una percepción efectiva conjunta).

Hay que considerar que el problema de las desigualdades de trato entre generaciones no es nuevo ni específico para el caso español, sino que resulta común a todos los sistemas de pensiones de reparto cuando se enfrentan al tipo de shocks demográficos que vienen afectando a todos estos sistemas, aunque con diferentes grados de intensidad, que es máximo en los casos con procesos de envejecimiento más violentos, como sucede en España. Esta problemática resulta especialmente aguda para los sistemas con prestaciones definidas (DB), aunque el modo en que trata de resolver el problema el sistema sueco de pensiones (con contribuciones definidas de tipo nocional, o no financiera: NDC) obliga a acumular fondos de estabilización de tal dimensión que lo que se gana en certidumbre y estabilidad se pierde en eficiencia y tasa de retorno, de acuerdo con los trabajos de Auerbach y Lee (2011).

Estos investigadores analizan mediante un modelo estocástico el problema en términos comparados, centrándose en tres variedades de sistemas de pensiones: el de la seguridad social norteamericana, el sistema alemán y el sistema NDC sueco. El resultado de su trabajo establece que el valor neto actual (NPV) de la diferencia entre contribuciones realizadas y pensiones percibidas a lo largo de la vida de una cohorte-tipo es sistemáticamente negativo: en torno al 6 por 100 del valor actual esperado de los ingresos totales de la cohorte a lo largo de su vida laboral ${ }^{37}$. Como en el trabajo se supone una carrera laboral de 47 años (entre 20 y 67), este desequilibrio equivale a 2,8 veces el ingreso medio anual, superior al del Régimen General español después de las reformas $\triangleright$

\footnotetext{
37 Véase Auerbach y Lee (2011; tabla 1, línea 1).
} 
propuestas, en que el superávit de 2066, en promedio de los dos supuestos de crecimiento, equivale a 2,2 salarios anuales (Cuadro 11, in fine).

Vale decir finalmente que ninguno de nuestros cálculos actuariales contempla la existencia de límites máximos a las pensiones, que afectan actualmente al 5,7 por 100 de las pensiones de jubilación en el Régimen General $(4,4 \text { por } 100 \text { en el sistema })^{38}$. A medida que se aplique la reforma, cierto número de pensiones sometidas al límite saldrán del mismo, aunque su cuantía no alcanza para modificar apreciablemente los cálculos medios.

Hasta aquí la propuesta de reforma del sistema español de pensiones para alcanzar en la medida de lo posible la sostenibilidad y la solidaridad intergeneracional, bajo la restricción de minimizar el desequilibrio en lo que se refiere a la solidaridad intrageneracional agregada, identificada aquí con la equidad actuarial. Pero ¿qué decir sobre su factibilidad social y política? ¿Es concebible esperar que las sucesivas generaciones de cotizantes, aunque no vean dañada fuertemente esta última, ratifiquen con su voto la pervivencia de un sistema con expectativas sustancialmente decrecientes?

Debe tenerse en cuenta que estas reformas implican la reducción hasta el 30 por 100 de la ratio legal de reposición en el momento de la jubilación en 2066 (con respecto a la actual). Mientras no se alcanza esa situación se produce una erosión del poder adquisitivo a lo largo del período completo de percepción que se sitúa en un 13,9 por 100 con respecto al del momento de jubilarse para quien lo haga

38 En junio de 2017 (con pensión máxima de 2.573/mes) su número es 230.870 , de un total de 4,08 millones en el Régimen General, y 254.945 de 5,8 millones en el conjunto del sistema: http://www. seg-social.es/Internet_1/Estadistica/Est/Pensiones_y_pensionistas/ Pensiones_contributivas_en_vigor/Por_tramos_de_cuant_al ESTC_005388 en 2044 (cuya esperanza de vida media llega hasta 2066, perdiendo en promedio un 9,4 por $100)$, colectivo que ya se jubilaría con una tasa legal de reposición inicial un 17 por 100 inferior a la actual (con pérdida media conjunta del 24,8 por 100). En cambio, la erosión del poder adquisitivo a lo largo del período completo de percepción es más intensa al comienzo del período considerado (de un 25 por 100 para los jubilados en 2018, con esperanza de vida hasta 2037 y una pérdida media del 17,4 por 100), a cambio de que estos últimos solo ven mermada su tasa legal de reposición inicial en un 0,5 por 100 (con pérdida media total de 17,8 por 100). Y lo contrario ocurre al término del período, en que el $I R$ se aproxima a la unidad $(0,9975)$. La combinación de las dos medidas se traduce en la reducción de la ratio media de reposición efectiva real en 19 puntos porcentuales hasta 2066 (Cuadro 9, 12. a fila), frente a un crecimiento proyectado de 36 puntos, de mantenerse la tendencia inercial (Cuadro 9, 2. ${ }^{\text {a }}$ fila).

Aunque todo esto sea en parte resultado de las desmesuras en las promesas temerarias hechas por el sistema político predemocrático (de muy difícil vuelta atrás en democracia), también se deben a una evolución demográfica mucho más adversa que la de los países de nuestro entorno. Siendo las reformas realizadas en estos países generalmente menos intensas que la que es preciso hacer en España, todas ellas se han visto acompañadas también de poderosos mecanismos para incentivar el ahorro privado, en orden a complementar las pensiones públicas, apelando a lo que en la arquitectura de los sistemas de pensiones de OECD/IDB/WB (2014, p. 49) se denomina «tercer pilar» (Diagrama 1) —cuando es voluntario-, o segundo pilar privado — cuando es obligatorio-, incentivándolo en uno y otro caso $\triangleright$ 


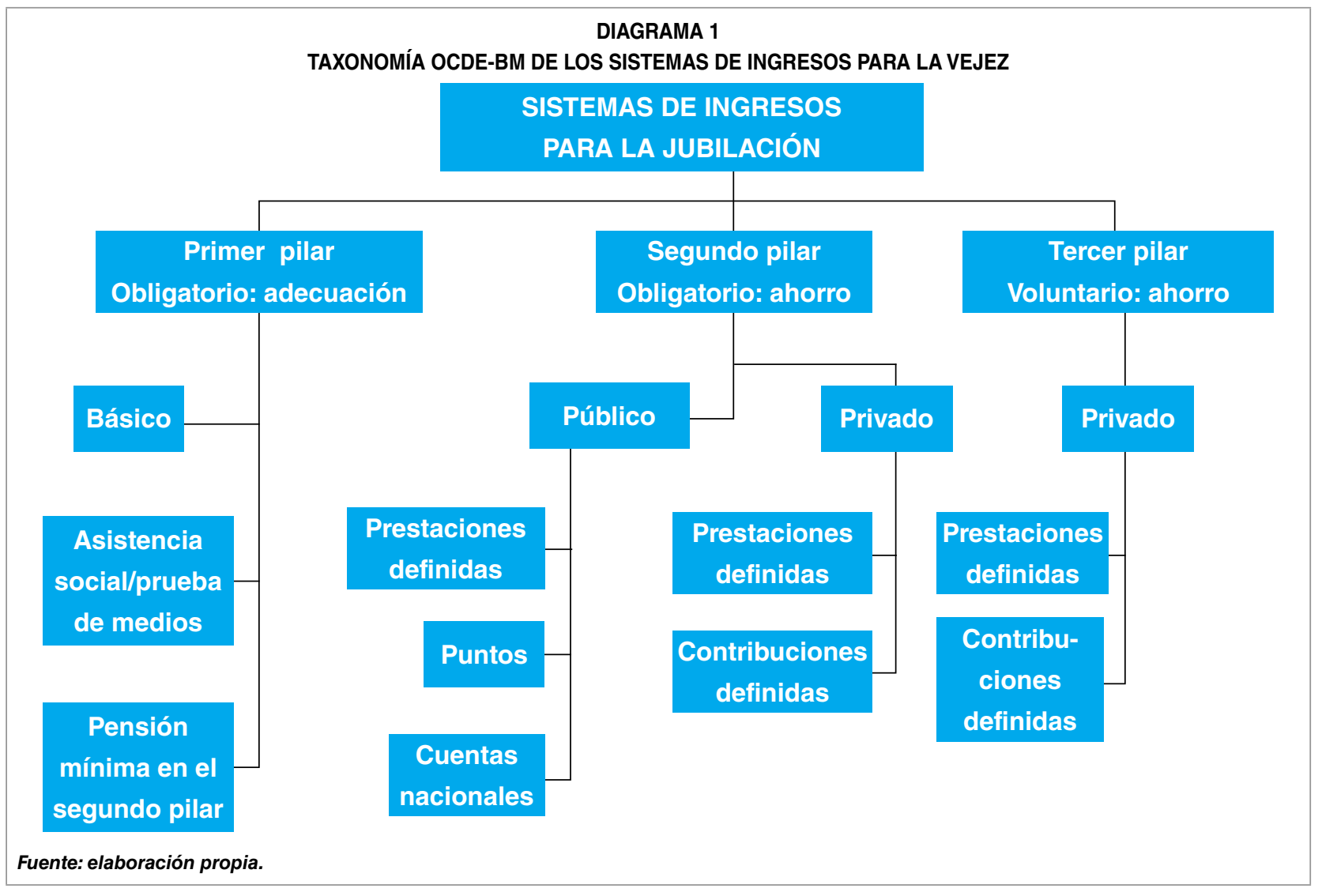

con fuertes apoyos de naturaleza fiscal (lo que se justifica, además, porque estos instrumentos potencian la riqueza nacional). Pero esto nos introduce en un mundo que ya no es el de las pensiones públicas del segundo pilar, sino el de fomento del ahorro privado en el mismo (ya individual, ya intermediado a través de la acción colectiva), o en el tercer pilar, que se desenvuelven con una lógica por completo diferente. Todo ello será tratado en un trabajo ulterior.

\section{Conclusión}

Antes de la reforma de 2013 el sistema español de pensiones contributivas resultaba abiertamente insostenible a medio y largo plazo por dos razones: a medida que la ratio de reposición pensión/salario vaya alcanzando los niveles establecidos por los parámetros legales, aumentará el desequilibrio actuarial entre el valor actual de lo cotizado y el de las pensiones percibidas, por lo que desaparecerá la equidad actuarial intrageneracional (considerando cada generación como un todo), ya dudosa en algunos supuestos. Además, aparecerá también un problema creciente para la sostenibilidad de este segundo pilar del sistema de pensiones y para la solidaridad intergeneracional, puesto que todas las previsiones indican que la relación cotizantes/pensionistas se reducirá en un tercio -al menos- durante los próximos cincuenta años, y eso tomando en consideración los efectos de la prolongación de los años cotizados y la reducción de los años de percepción de la pensión derivadas de la reforma de 2011 (y de su eventual prolongación hasta alcanzar la edad legal de jubilación a los 70 años en 2063). 
Los dos instrumentos de corrección introducidos por la reforma de 2013 - a saber: el factor de sostenibilidad (FS) y el nuevo índice de revalorización (IR) - deben ser revisados, ya que: a) el primero es inconsistente, puesto que la corrección de la ratio de reposición pensión/ salario se hace depender de la evolución de la esperanza de vida del jubilado, que ya ha sido neutralizada por la reforma de 2011 (y su eventual prórroga); b) el IR introducido en 2013, por mucho que su aplicación pudiera acabar corrigiendo el desequilibrio entre ingresos y gastos al término del período proyectado - subsanando previamente el problema de cálculo derivado del razonamiento circular que contiene-, no evitaría incurrir en un voluminoso déficit durante el largo período de transición (sin poner medios para enjugarlo), ni cumpliría tampoco los requisitos mínimos que debe reunir una reforma de este tipo, especialmente el gradualismo y la distribución intergeneracional equitativa.

La reforma que se propone en este trabajo contiene cuatro medidas:

1. Prorrogar a partir de 2028 el retraso en la edad legal de jubilación, pero solo a razón de un mes por año (no dos), con lo que se situaría en 70 años en 2063.

2. Sustituir el factor de sostenibilidad (FS) de la Ley 23/2013 por una disminución paulatina de la ratio de reposición legal, desde el 100 por 100 de la base reguladora actual hasta el 70 por 100 en 2057, reduciendo 0,5 puntos porcentuales al año entre 2018 y 2037 y un punto porcentual entre 2038 y 2057.

3. Sustituir el índice de revalorización (IR) de la Ley 23/2013, de carácter indeterminado, por una revalorización con pérdida programada del poder adquisitivo de intensidad decreciente hasta el final del período proyectado: arrancando con un $I R$ equivalente al porcentaje de inflación menos 1,75 puntos porcentuales, reduciendo este corrector en 0,0306 puntos/ año entre 2018 y 2066.

4. Aplicar a la pensión de viudedad la regla de reducción del 50 por 100 cuando se compatibiliza con una pensión contributiva propia o un salario pleno, en paralelo con lo que sucede actualmente con la pensión de jubilación.

Las proyecciones realizadas en este trabajo indican que con esta cuádruple reforma el sistema español de pensiones contributivas recuperaría su carácter sostenible, lo que se comprueba calculando su impacto previsible sobre el conjunto de las pensiones contributivas y sobre las de jubilación en el Régimen General, hacia el que converge todo el sistema, una vez eliminado del cómputo de gasto contributivo el complemento a mínimos, que se financia ya con cargo a los presupuestos del Estado. Debe tenerse en cuenta que, a medida que vaya aplicándose la reforma, el coste de este complemento probablemente aumentará, al beneficiar a una proporción mayor de pensiones.

Además de garantizar la equidad intergeneracional, la reforma minimizaría la eventual reducción en la equidad actuarial intrageneracional. Tal reducción podría compensarse, además, a través del tercer pilar del sistema, fomentando la acumulación de fondos de pensión privados compensatorios con fuerte apoyo fiscal durante el período de transición, lo que se estudiará en otro trabajo.

\section{Bibliografía}

[1] AUERBACH, A.J. y LEE, R. (2011). «Welfare and generational equity in sustainable $D$ 
unfunded pension systems». Journal of Public Economics, vol. 95, n.1, pp. 16-27. (2 de febrero). Disponible en: https://www.ncbi.nlm. nih.gov/pmc/articles/PMC3148111/

[2] BRíO, J. F. y GONZÁLEZ, M. C. (2016). «Un ejercicio de la aplicación del modelo de colas a la sostenibilidad del sistema de pensiones español». Presupuesto y Gasto Público, n.ㅇ 85, pp. 125-143.

[3] COMISIÓN EUROPEA (2015a). The 2015 Ageing Report: Economic and budgetary projections for the 28 EU Member States (20132060). European Economy 3/2015. Disponible en: $h$ ttp://ec.europa.euleconomy_finance/publications/european_economy/2015/pdf/ ee3_en.pdf

[4] COMISIÓN EUROPEA (2016). European semester thematic fiche. Adequacy and sustainability of pensions. Disponible en: http:// ec.europa.eu/europe2020/pdf/themes/2016/ adequacy_sustainability_pensions_201605.pdf

[5] ESPINA, Á. (2017a). «La reforma de las pensiones y el Estado de Bienestar: un marco conceptual». Boletín ICE n.․ 3085 (marzo de 2017). Disponible en: $h t t p: / / w w w . r e v i s t a s i c e$. com/CachePDF/BICE_3085___9FC93AC 67D2F1855801439D5FA3FFDD2.pdf

[6] ESPINA, Á. (2017b). «El sistema español de pensiones en el siglo XXI: Evidencia disponible y análisis gráfico». Cuaderno de Documentación n. 110, (6 de abril 2017), Dirección General de Política Económica, Ministerio de Economía, Industria y Competitividad. Disponible en: http://imagenesbibliotecacentral.minhap.gob.es/pdfpublicaciones//Literaturagris/cd110_2017.pdf

[7] JIMENO, J. F. (2003). «La equidad intrageneracional de los sistemas de pensiones", Revista de Economía Aplicada, no 33, vol. XI, pp. 5-48. Disponible en: $h t t p: / / w w w . r e v e c a p$. com/revista/numeros/33/pdf/jimeno.pdf

[8] KOZLOWSKI, J. VELDKAMP, L. y VENKATESWARAN, V. (2015). The Tail that Wags the Economy: Belief-Driven Business Cycles and Persistent Stagnation (9 de junio). Disponible en: http://www.imf.org/external/np/seminars/eng/2015/secularstag/pdf/ Venkateswaran.pdf

[9] LLORENTE, A. Y MORENO, C. (2017). «La protección de la viudedad en [ocho] países de nuestro entorno". Revista del Ministerio de Empleo y Seguridad Social, pp. 19-45.

[10] LÓPEZ CUMBRE, L. (2014). «Pensiones mínimas y complementos para mínimos» Ponencia al XI Congreso AESSS ( 1 de septiembre de 2014). Disponible en: http:// www.aesss.org/2014/09/ponencia-profa-lopez-cumbre-al-xi-congreso-aesss/

[11] MENEU, R.; DEVESA, E.; DEVESA, M.; DOMÍNGUEZ, I. y ENCINAS, B. (2017). «Adjustment mechanisms and intergenerational actuarial neutrality in pension reforms". International Social Security Review, vol. 69; n.-1, pp. 87-107, (enero-marzo).

[12] MINISTERIO DE EMPLEO Y SEGURIDAD SOCIAL (2017). Monográfico sobre la Pensión de Viudedad, ㄲo 129/2017.

[13] MINISTERIO DE EMPLEO Y SEGURIDAD SOCIAL (2017). Presupuestos de la seguridad social para el año 2017. Cifras y datos. Disponible en: http://www.seg-social. es/prdioo/groups/public/documents/binario/226964.pdf

[14] MORAL-ARCE, I. y GELI, F. (2015). «El Índice de Revalorización de las Pensiones (IRP): Propuestas de solución del problema de circularidad». Documentos de Trabajo DT/2015/1, AIReF.

[15] OECD (2005). Pensions at a Glance. Public policies across OECD countries.

[16] OECD/IDB/WB (2014). Pensions at a Glance: Latin America and the Caribbean. Disponible en: http://dx.doi.org/10.1787/ pension_glance-2014-en

[17] OECD (2015). Pensions at a glance, 2015. $O E C D$ and $G 20$ Indicators.

[18] PATXOT, C.; SOLÉ, M. y SOUTO, G. (2017). «Should pensions be redistributive? The impact of Spanish reforms on the system's sustainability and adequacy". Documento de Trabajo: FEDEA 2017/02. Disponible en: http:// documentos.fedea.net/pubs/dt/2017/dt201702.pdf

[19] RABANAL, P. F. (2017). «La pensión de viudedad en la doctrina del Tribunal Constitucional»». Revista del Ministerio de Empleo y Seguridad Social, pp. 155-176.

[20] ROCH, O.; BOSCH-PRINCEP, M.; MORILLO, I. y VILALTA, D. (2015). «Una revisión del índice de revalorización de las pensiones $\triangle$ 
Álvaro Espina

españolas (A Revision of the Revaluation Index of the Spanish Pensions)». SSRN. (9 de enero). Disponible en: https://papers.ssrn. com/so/3/papers.cfm?abstract_id $=2547808$

[21] SÁNCHEZ, A. R. (2014). «The Automatic Adjustment of Pension Expenditures in Spain: An
Evaluation of the 2013's Pension Reform». Documentos de Trabajo, n.․ 1420. Banco de España. Disponible en: http://www.bde.es/f/ webbde/SES/Secciones/Publicaciones/ PublicacionesSeriadas/DocumentosTrabajo/ 14/Fich/dt1420e.pdf 